\title{
REVIEW
}

\section{The avoidability of head and neck injuries in ice hockey: an historical review}

\section{N Biasca, S Wirth, Y Tegner}

Br J Sports Med 2002;36:410-427

The number of minor traumatic brain injury (mTBI), cerebral concussions, is increasing and cannot be eliminated by any kind of equipment. Prevention strategies, such as the introduction of "checking from behind" rules have become effective in decreasing the number of severe spinal injuries. A new "head checking" rule should reduce mTBI in the same way in the following years. Mouthguards should be mandatory as an effective device for the prevention of dental and orofacial injuries, as well as reducing the incidence and severity of mTBI. A new internet database system, the International Sports Injury System (ISIS) should improve epidemiological analysis of head, face, and spinal injuries worldwide. ISIS should provide an internationally compatible system for continuous monitoring of risk factors, protective effects of equipment, and protective effects of equipment and effects of changes in rules through the years.

See end of article for authors' affiliations

Dr Biasca, Head of Orthopaedic Surgery Co-Head of Trauma Surgery, Spital Oberengadin, $\mathrm{CH}-7503$ Samedan, Switzerland

Accepted 26 March 2002 ce hockey is a fast sport with a risk of injury as an integral part of the game. To reduce the risk of injuries, various types of protective equipment have been developed. However, this equipment should neither be a source of new injuries nor compromise the nature of game. In attempting to eliminate one risk, other risks may be created and the nature of the game may be influenced. The injury pattern of head and neck injuries has changed since the introduction of helmets and full facemasks. To meet the needs of an expanding ice hockey population, equipment manufacturers began to produce more encompassing body protection. Shoulder pads became large, covering the shoulder, chest, and half of the back with a hard shell. Elbow pads became sizeable, and their hard shell became a new weapon in the player's arsenal. Parallel to the better design and resilience of elbow and shoulder pads, the increased aggressiveness and the feeling of invincibility of the players paradoxically contributed to increase the risk of head and neck injuries. Catastrophic injuries, such as subdural haematoma and blinding, were reduced in the period 1963-1991 as a result of the compulsory wearing of helmets and full facemasks. ${ }^{1-6}$ Despite this, the incidence of head injuries is now increasing. ${ }^{7-20}$ Head and face currently represent the most common location of ice hockey injuries. ${ }^{7-10}$ World wide, there is also an increasing incidence of minor traumatic brain injuries
(mTBI), even called cerebral concussion. ${ }^{7-20}$ Parallel to this, in the period 1982-1996, there was world wide a persistent number of 17 major spinal injuries a year. ${ }^{21-26}$ These epidemiological data are very worrying and need to be analysed. The development of protective equipment requires a sound understanding of the injury mechanism, location, and type as well as the tissue response to stress, fatigue, and displacement velocity or acceleration. There is also the necessity to continuously analyse the epidemiological data with respect to the evolution of protective devices and ice hockey rules. The use of a uniform computerised www.ISIS (International Sports Injury System) based database is one way of detecting changes in the epidemiological pattern early on. ${ }^{27}$

\section{HISTORICAL REVIEW}

The beginnings of North American ice hockey have been traced back to 1783 when British troops used the natural arena of frozen ponds and rivers to ease the bleakness of winter. ${ }^{2}$ In the 1920s, padding was minimal and worn as much to keep warm as to diffuse the blows of sticks and pucks. Players started to wear pants and soccer shin guards for leg protection. The large open areas of ice used for outdoor games facilitated a more open style of play which may account for the lack of concern about injury.

In 1929 the first facemask with leather was introduced for use by a goaltender to cover a broken nose, but, as vision was impaired, it was not used. ${ }^{2}$ Jacques Plante, goaltender of the Montreal Canadians, started wearing a mask during games after he was hit on the nose by a slap shot from Ranger Andy Bathgate. ${ }^{2}$ Head protection for goaltenders was met with mixed reviews, and it was not common in the National Hockey League until the North Star Bill Masterson was struck on the head by a puck and died. ${ }^{2}$

In the late 1930s shoulder protections with a leather cap added began to appear. ${ }^{2}$ Elbow pads were fashioned from leather tubes filled with horsehair. ${ }^{2}$

In the late 1940s, hard plastic shoulder pads for football were covered with foam rubber and sometimes used in ice hockey. ${ }^{2}$ Hard caps with foam covering also served as elbow pads. ${ }^{2}$ Hockey gauntlets with leather palms and a cloth covered wrist guard made of bamboo strips formed the wrist-hand protection. ${ }^{2}$ The first head protection appeared in the 1950s. It had squares of leather with thin felt backing for comfort and was worn on the forehead and back of the head (fig l).

When the game moved indoors, after the second world war, the play was more constricted 


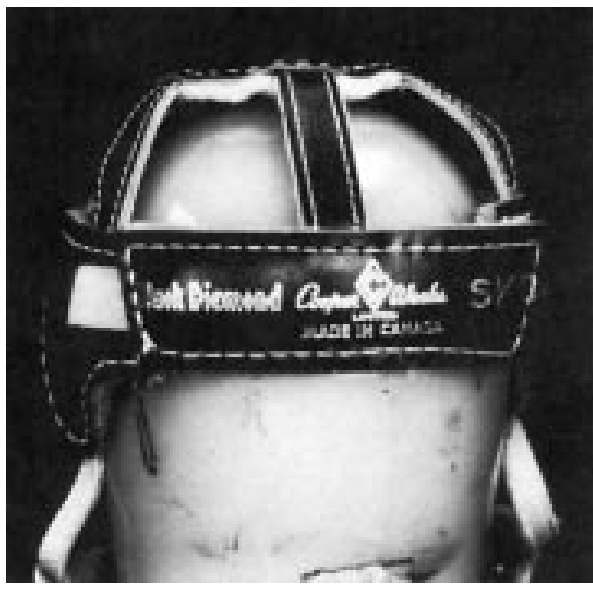

Figure 1 Helmet of the late 1950s. ${ }^{2}$

and the extra clothing and padding were hot and cumbersome. ${ }^{2}$ The first artificial ice surface for indoor hockey opened 5 January 1912 in Vancouver with a series of rinks and leagues operating that year both in the West and East. The introduction of the slap shot in the 1950s created new challenges for the goaltender and changed the game. ${ }^{2}$ Up to this point, raising the stick above the shoulder drew a two minute penalty. Players started to heat the stick blade in hot water forming the first curved blade. ${ }^{2}$ Whipping the puck rather then shooting it made the puck dip and drop unexpectedly, which was a new challenge for the defence. Although written injury information is not available, it appears that when hockey was played outdoors on the large ice sheets with limited boundary materials, injuries were not a great concern. ${ }^{2}$ As the game moved to the enclosed indoor arena, play was more interactive between players and the environment. High flying pucks and sticks resulted in a high risk of above the shoulder injuries. ${ }^{2}$

The first catastrophic injury-the loss of an eye-occurred in $1929 .{ }^{2}$ After this, the NHL rules did not permit players to play with only one eye. ${ }^{2}$ The same rule was applied in the Canadian Amateur Hockey Association (CAHA) at the end of 1920s, when a player from Ontario, named Trushinski, suffered an injury to one eye and later to his other eye, leaving him legally blind. ${ }^{4}$ One eyed players were no longer permitted to play in the CAHA. The list of players who were blinded, ending promising careers, is extensive. ${ }^{428}$ The incidence of above the shoulder injuries was high not only in the professional leagues but also in the amateur ones. ${ }^{29}$ Eyes were permanently damaged, teeth were knocked out, and many players had scarred faces from lacerations. ${ }^{2}$ Missing teeth and facial scars were the mark of a hockey player. $^{2}$

The history of helmets and face protectors represents the best example of the evolution of hockey protective equipment.

\section{HELMETS AND FACE PROTECTORS \\ Helmets}

The use of hockey helmets began in Sweden in the middle of the 1950s. An insurance survey in 1961 found over 100 closed head injuries, with one death, 22 mTBIs, and three facial fractures; it also found that the number of serious head injuries in ice hockey was increasing. ${ }^{3}$ This survey led to the development of hockey helmets, the use of which became mandatory in Sweden in 1963. ${ }^{3}$ All players taking part in matches in Sweden were obliged to wear a helmet that had been tested and certified by the Swedish Hockey Association (fig 2). The first rules were formulated for testing and certifying helmets.

In 1965 the CAHA made helmet wearing mandatory for all non-adults. ${ }^{24}$ Subsequently the Amateur Hockey Association

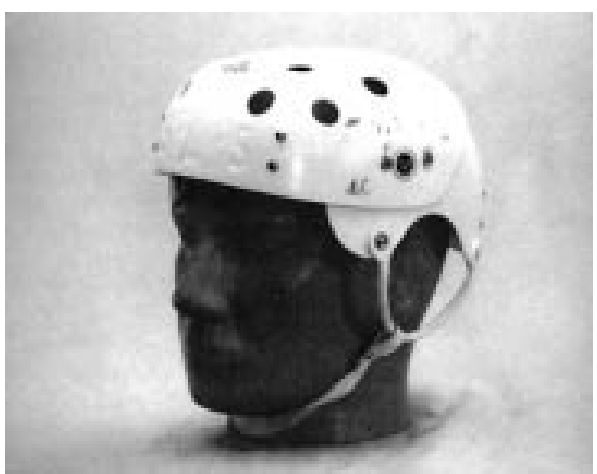

Figure 2 Adjustable helmet with a liner of the cradle type, certified in 1963.

of the United States (AHAUS) established a new rule requiring players to wear other head protection as well. ${ }^{24}$ In 1968 Fekete $e t a l^{30}$ reported on two teenage ice hockey players in Canada who died after closed head injuries while wearing helmets. This led to a request by the CAHA to form a technical committee for approving helmets. A Canadian Standards Association (CSA) technical committee was charged with this in $1969 .{ }^{4}$ In 1975 all CAHA players were required to wear these CSA approved helmets.

\section{Face protectors}

The first face protectors developed in 1972 were an excellent start toward ensuring adequate eye protection for hockey players, including goaltenders. Many goaltenders wore moulded plastic face protectors, and other players wore wire grid face protectors. ${ }^{2}$ Unfortunately the blade of a hockey stick could still penetrate many of the face protectors and could result in a serious eye injury. ${ }^{4}$ In 1973, forwards and defencemen wore no eye protection, although some goaltenders were wearing moulded masks introduced by Jacques Plante. In a retrospective questionnaire study involving 600 Canadian ophthalmologists, 287 eye injuries were found, including 20 blinded eyes. ${ }^{4}$ Three quarters of these injuries were stick induced. The consequence of this survey was that in 1975 the CAHA introduced high sticking penalties, which prohibited the carrying of sticks above shoulder level. ${ }^{4}$ In 1974 Pashby ${ }^{4}$ began a prospective study on this topic. In the season 1974-1975, there were 43 blinded eyes, and the puck caused $38 \%$ of these injuries. It was evident that some type of eye protection was necessary. The eye and face protectors available were unsuitable because the hockey stick blade could penetrate them immediately over the eye area. The CSA technical committee was charged with investigating standards for ice hockey visor and face protectors. In 1976 the AHAUS required all amateur players under the age of 20 to wear a full facemask. ${ }^{4}$ In 1978, the CAHA required all hockey players playing under their jurisdiction to wear a CSA certified face protector attached to a CSA certified helmet. ${ }^{4}$ This rule was not compulsory for senior and junior players. To ensure that only CSA certified protectors were available in Canada, the Canadian government ruled that only certified protectors could be imported into or sold in Canada. At the same time, Dr Paul Vinger of Boston was asking the American authorities to make eye protectors mandatory equipment in US hockey also. ${ }^{4}$ In the 1977-1978 season, the National Collegiate Athletic Association (NCAA) required full facemasks to be worn in all college hockey games in the United States. ${ }^{28}$ In Sweden, there was a similar development, and since the 1987-1988 playing season it has been mandatory for senior players (born after 1966-1967) to wear visors (fig 3). ${ }^{2}$

Ice hockey eye injuries gained further international prominence in 1978 when the first international ice hockey doctor's 


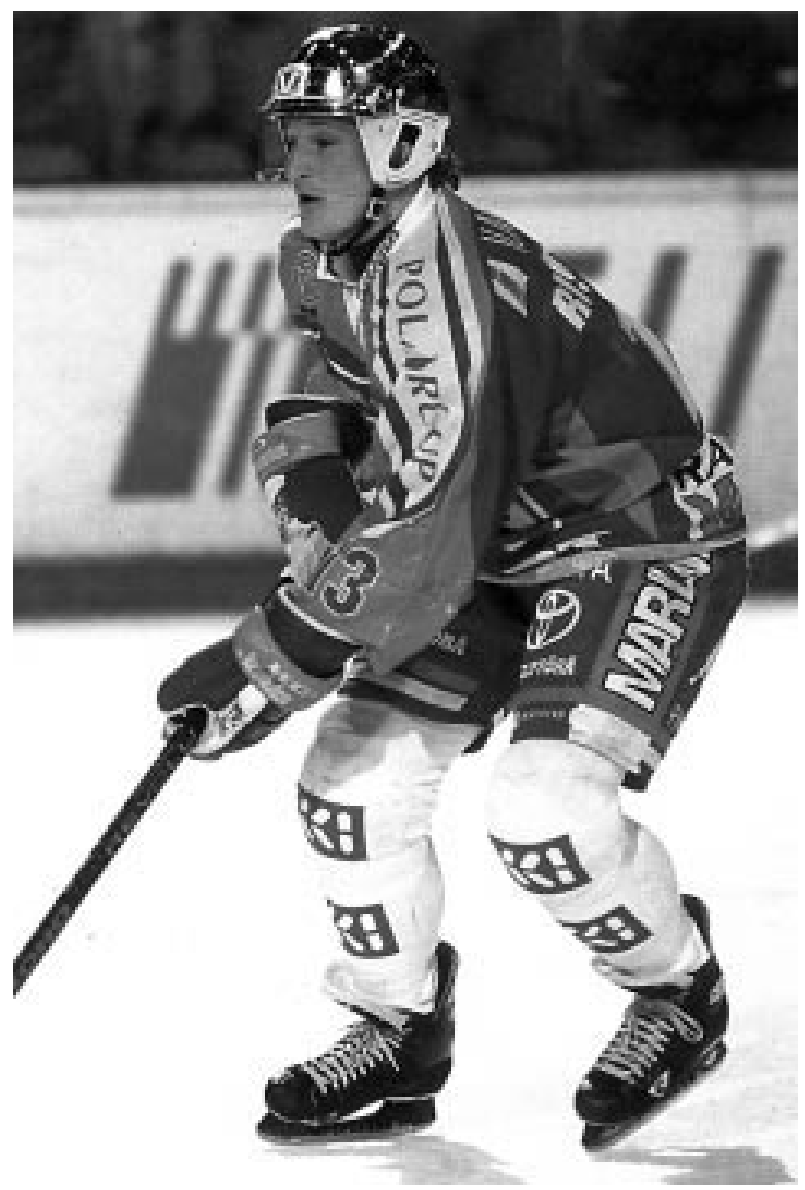

Figure 3 Player wearing a standardised helmet with a visor.

conference of the International Ice Hockey Federation (IIHF) took place in Prague, Czechoslovakia, under the chairmanship of Dr Tintera during the world ice hockey championships 1978. ${ }^{4}$ The European and American doctors were most impressed, and the use of eye protectors for hockey players became common in all hockey playing countries. Wearing of a full facemask was then mandatory for juniors in European countries from 1978. ${ }^{4}$ Helmets were not required in the professional leagues until 1981..$^{28}$

Over the years, the Canadian subcommittee on head and face protectors for ice hockey goaltenders have developed a standard for goaltenders, which was completed in $1996 .{ }^{31}$

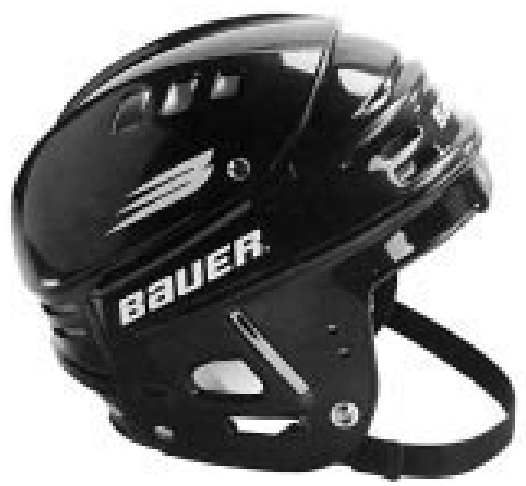

Figure 4 Bauer hockey helmet $\mathrm{HH} 5000$ : an example of a standardised helmet (CSA, HECC, and CE certified) with outstanding comfort and look, protection, optimum fitting, and lightweight performance.

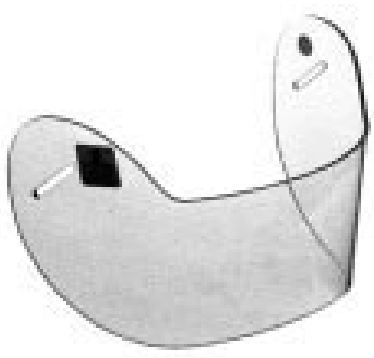

Figure 5 An example of a standardised hockey visor (CSA HECC, and CE certified) with professional look and protection.

Continued helmet, full facemask, and visor improvements have been the result of testing by researchers, collaborative efforts between manufacturers and both hockey and standards organisations, and the use of new materials.

\section{International standards for ice hockey helmets and face protectors}

The creation of the International Organization for Standardisation (ISO), whose mandate has been to facilitate the international cooperation and unification of industrial standards, officially began its operations on 23 February 1947. In 1979, at the annual AHAUS meeting in Lake Placid, it became apparent that an ISO for hockey helmets and hockey face protectors was needed. ${ }^{5}$ The inaugural meeting of ISO/TC83/SC5 was conducted in March 1987 in Ottawa, Canada, and it developed the first ISO draft standards on hockey helmets and face protectors. Since 1987, the subcommittee SC5 has met annually. ${ }^{5}$ As a result of the Treaty of Rome, the EU decided to harmonise the requirements throughout Europe to remove obstacles to the free movement of goods. ${ }^{32}$ After the enforcement of the EU directives in 1989, the European Commission and the European Free Trade Association (EFTA) mandated the technical committee (CEN/TC158) of the CEN (European Committee for Standardisation) to prepare European standards. In October 1996, the ISO published the first international standards (ISO 10.256 and 10.257), which addressed head and face protection of ice hockey players. ${ }^{33}$ The Committee Européen de Normalisation (CEN) published at the same time a European standard (EN 967), which also addressed the subject of head and face protection for ice hockey players ( fig 4 ). ${ }^{33}$

After the meeting of the SNV (Swiss Association for Standardisation) in October 1996 in Zurich, Switzerland, the members of the two standard association committees, ISO and CEN, realised that they would have to combine their standards in order to develop a single international approved standard..$^{33}$ A European committee (CEN TC 158) was founded to develop a single international standard for head and face protection of ice hockey players and was sent to all ISO members (figs 5 and $6)$.

Today there are four official standards for ice hockey head and face protection (CEN, ISO, CSA, and ASTM) (table 1).

If the committee members of the ISO and CEN approve the proposed single international standard, by the end of 2002 there will be a single international standard for head and face protection (ISO/EN 10256). ${ }^{33}$

\section{RESULTS OF RULES AND PLAY CHANGES}

\section{Head injuries}

Before the introduction of full facemasks and helmets, head injuries, including face, scalp, and brain injuries, accounted for at least $50 \%$ of all serious injuries in ice hockey. ${ }^{4}$ Before the use of any type of hockey helmets and before the mandatory use of standardised helmets, there were deaths from head injuries in Sweden, Canada, and United States. ${ }^{4}$ However, these data go back to the 1960s. Since 1963 there have been no deaths from head injury reported in Sweden. ${ }^{3}$ 


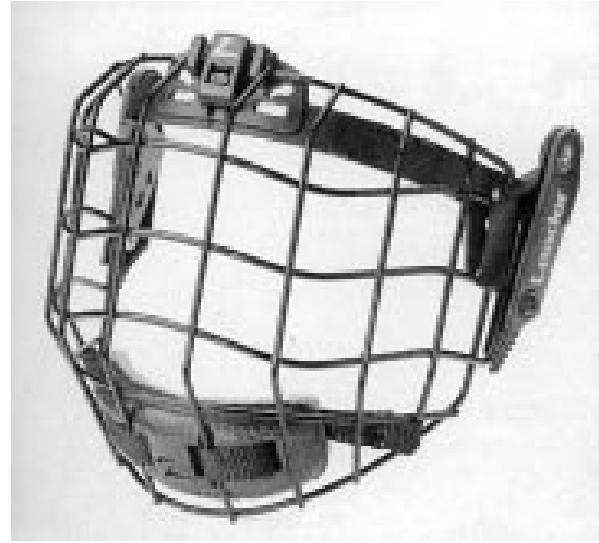

Figure 6 An example of a standardised hockey full facemask (CSA, HECC, and CE certified) with increased protection for the ear and chin.

The problem of head protection in ice hockey is unique because of the demands of the player to wear small and lightweight helmets to be used to protect against high sticks, strikes against the board, ice surface, or glass and collisions, which often result in severe head injuries.

To analyse the effectiveness of hockey helmets, it is necessary to classify head injuries as described by Patrick Bishop. He classified them into two types: focal head injury, in which the trauma is localised to a specific region of the head; diffuse head injury, involving widespread neural disruptions of the brain. ${ }^{34}$

\section{Focal head injuries}

Focal head injuries are caused by the force of contact and the head acceleration of direct blunt trauma, such as being struck with a hockey stick or a puck, or falling on the ice surface and striking the head. This type of focal injury generally includes skull fractures and intracranial haematoma (epidural or subdural haematoma, intracranial haemorrhage) (figs 7 and 8). It is estimated that about $50 \%$ of hospital admissions for head injury and nearly $66 \%$ of head injury deaths are related to focal injury. Wearing an internationally approved standardised helmet can reduce these injuries. ${ }^{34-36}$

\section{Diffuse head injuries}

Diffuse head injuries, on the other hand, are caused by the inertial effect of the mechanical blow to the head. These injuries may involve axonal damage from excessive angular acceleration-for example, after an abrupt body checkcaused by either direct or indirect inertial loading of the head. They represent a continuous spectrum of the same pathology: a progressive widespread but heterogeneous shearing of axons, throughout the white matter of the cerebral and cerebellar hemispheres up to the brainstem. They are characterised by a more widespread or global disruption of neurological function. The proportion and total number of axons damaged, as well as their anatomical location, determines the severity and reversibility of the clinical syndromes and the neurological deficits. The exact subcellular events and their time course in the injured axons are not $100 \%$ clear. The degree of severity of traumatic axonal damage can range from transient disturbance of ionic homoeostasis to swelling and impairment of axoplasmic transport with a secondary (delayed) axotomy, which finally leads to structural irreversible lesions. ${ }^{37} 38$

Sequelae of these injuries can range from recovery for a "concussion" to either coma and/or death. These injuries account for only about $25 \%$ of head injury deaths, but they are considered more serious because of permanent neurology disability in survivors. Furthermore they are characterised by a cumulative effect, which may end an athlete's career. $^{9-11} 1739$ 40-42
An mTBI, even called concussion, may represent the mildest form of a diffuse brain injury. ${ }^{37}$ The persistently high incidence of mTBI, concussions, over the last few years is alarming. In the Canadian Hockey League (CHL) the incidence of mTBIs rose from $4 \%$ in the period $1991-1996$ to $8.5 \%$ in the season $1997-$ 98. ${ }^{7}$ The National Collegiate Athletic Association (NCAA) injury surveillance system recorded a comparable development in North America. ${ }^{8}$ Similarly in Sweden, according to Tegner and Back, ${ }^{18}$ one Swedish ice hockey team showed an increasing incidence of mTBI in the last 15 years from $2 \%$ of all injuries in the season $1986-1987$ to $18 \%$ in the season $2000-2001 .{ }^{18} \mathrm{John}$ Powell reported a distinct increase in the incidence of minor traumatic brain injury in the professional ice hockey league (NHL), from 2\% in the season 1989-1990, to 4.9\% in 1995-1996, to $8 \%$ each in the last two seasons 1999-2001. ${ }^{43}$ mTBI represented one fifth of all head injuries in the Swiss National Ice Hockey leagues A and B during the seasons 1996-1998 (fig 9). ${ }^{9}$ According to national and international statistics the proportion of mTBI in ice hockey to the overall number of injuries fluctuates between 2\% and 20\%. ever, the diagnosis of mTBI is subject to widespread misunderstanding in definition and severity, which have contributed to a paucity of reliable epidemiological data.

Often the mechanism of a head injury is complex involving a focal and a diffuse component. Direct head contact can induce both rotational acceleration of the head necessary to cause a diffuse injury and the conditions necessary to cause a focal injury. Hockey helmets were originally developed to protect against brain injury death and/or intracranial haematoma and to reduce the risk of serious head injuries precipitated by direct blunt traumas. ${ }^{2-5} 1517$ Helmets provide such protection by means of a firm outershell, intended to distribute the load over a wider area, and by means of an energy absorbing liner system. ${ }^{34-36}$ All hockey helmets are evaluated and tested using a collision simulation model that accounts for direct loading of the head by blunt trauma. ${ }^{32}$ 34-36

In cooperation with Professor Bishop, we analysed the videotapes of forty professional ice hockey players, who sustained a an mTBI in the NHL. We proposed three different possible mechanisms responsible for causing mTBI in ice hockey: $(a)$ a direct eccentric blow to the head; $(b)$ a direct blow to the face or jaw, and $(c)$ a blow directed to the chin.

(a) A direct blow to the head may cause many forces to the brain tissue. These forces may be simplified to a force $\mathrm{F}_{\mathrm{t}}$, with translatory components (with transversal and axial forces), and a force $\mathrm{F}_{\mathrm{r}}$, with rotatory components in the frontal, sagittal, and transversal (horizontal) planes (fig 10).

(b) A direct blow to the face or jaw may cause a force $F_{t}$ with translatory and a force $\mathrm{F}_{\mathrm{r}}$ with rotatory components as well. In ice hockey there is a lot of contact with the jaw and face, a similar mechanism to the knockout punch in boxing, and the result is often significant rotational acceleration of the head and brain. However, there is no protective mechanism that can reduce the effects of this force (fig 11).

(c) A blow directed to the chin may cause a translatory force $F_{t}$, which is transmitted from the chin through the lower jaw, through the temporomandibular joint at the base of the skull, and then to the brain. These forces may also cause wave propagation through the brain and may cause concussion as well (fig 12).

Improvements in the padding materials used for hockey helmets have been made recently. ${ }^{35}{ }^{36}$ Such materials are usually made from urethane foams with a thickness of about 16 $\mathrm{mm}$. Over the past few years, polypropylene, a lighter and more effective energy dissipating material than urethane foam, has been introduced in some helmet models. Although the padding materials in helmets have been improved to absorb more energy, the crucial factor in mTBI appears to be rotational acceleration of the brain. ${ }^{11} 1517203436-384044$ 
Table 1 Official standards for ice hockey head and face protection (CEN, ISO, CSA, ASTM)

CEN European Standard

- EN 967:96 for "Head protectors for ice hockey players"

(Includes helmets, visors and full facemask for players, goaltenders, and functionaries)

ISO International Standards

- ISO 10256:96 for "Protective helmets for ice hockey players"

(For players, goaltenders, and functionaries)

- ISO 10257:96 for "Face protectors and visor for ice hockey players"

(For players, goaltenders, and functionaries)

Canadian Standards

- CAN/CSA Standard Z262.1-M90 for "Ice hockey helmets"

- CAN/CSA Standard Z262.2-M90 for "Face protectors and visor for ice hockey players"

- CAN/CSA Z262.3-M96 for "Head and face protectors for ice hockey goaltenders"

American Standards

- ASTM Standard F1045-90: "Standard performance specification for ice hockey helmets"

- ASTM Standard F513-89: "Standard performance specification for ice hockey full facemask"

- ASTM Standard F1587-96: "Standard performance specification for helmet and facemask for ice hockey goaltender"

- ASTM Standard F737-86: "Standard performance for skate blades"

The two most critical properties of helmets are impact energy attenuation and load distribution. These properties reduce the magnitude of the forces applied to the head reducing the stress and strain in the skull and brain. ${ }^{46}{ }^{47}$ Through this mechanism, more serious head injury may be prevented and the severity of an mTBI may be reduced. ${ }^{46}$ The magnitude of the acceleration required to produce an acute brain injury has been shown to vary with the duration and direction of the acceleration. ${ }^{47}$ Results from these experiments led to the publication of tolerance curves and severity indices to distinguish impact with high likelihood of producing injury from those with a low likelihood. ${ }^{48}{ }^{49}$ Two such indices, the Gadd severity index and the HIC score, are currently used to determine the likelihood of a serious brain injury. ${ }^{49}$ A Gadd score of 1500, a HIC score of 1000 , or a peak acceleration of $200 \mathrm{~g}$ are considered threshold values for a single impact to be likely to cause a severe brain injury. Moreover, engineers and manufacturers have used these indices to better determine the injury potential of impact associated with lower acceleration but a more prolonged duration. ${ }^{47}$ Previous studies have shown that repeated impacts at subconcussive threshold levels may have a cumulative deleterious effect both histopathologically and on cognition, even if no sin-

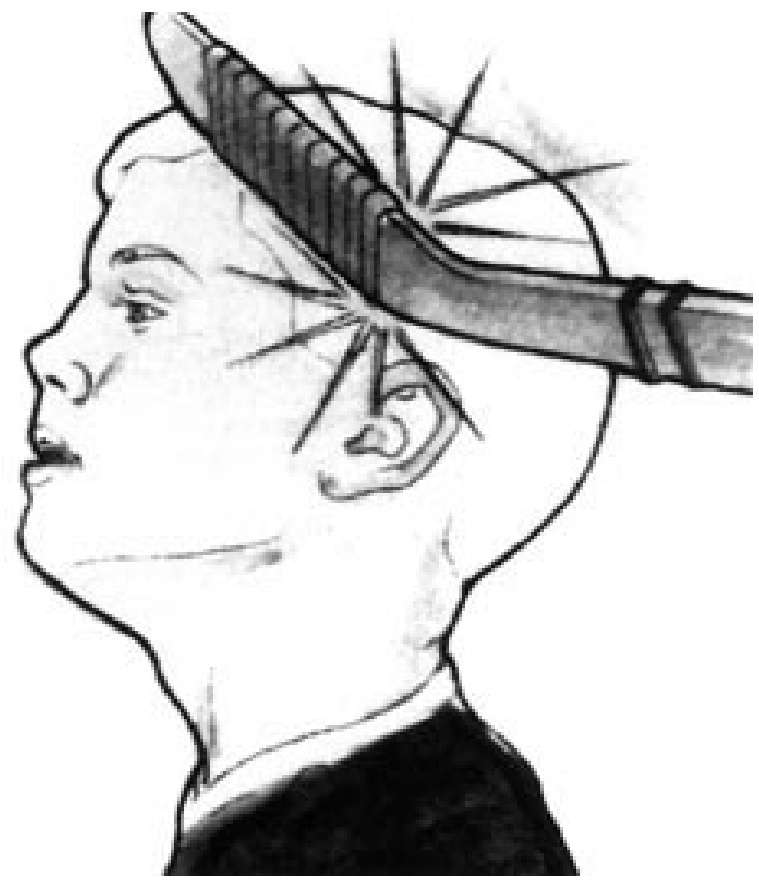

Figure 7 A high stick injury to one of the most dangerous areas of the head with the possibility of causing an epidural haematoma.' gle event led to neurological signs or symptoms. ${ }^{37}{ }^{47}$ The critical acceleration threshold that would be likely to lead to cumulative neurological dysfunction is currently not known.

The current standards require a drop test with a pass/fail criterion of 275-300 g headform acceleration. However, current research shows that a minor traumatic brain injury, a concussion, is probable at a head acceleration in the 150-200 g range. ${ }^{46}$ Therefore, the assessment criterion may not drive helmet improvement and a greater potential reduction in mTBI. ${ }^{46}$ Further examination of the impact characteristic in sports-for example, impact energy, location, and frequencyand their relation to mTBI are necessary. ${ }^{46}{ }^{47}$ Further research with a match video and the use of an internet based database system is an invaluable adjunct.

Naunheim et $\mathrm{l}^{47}$ found that peak acceleration measured at the surface of the head was $160-180 \%$ greater from heading a soccer ball than from a non-injurious impact during hockey or American football. ${ }^{47}$

The ability of hockey helmets to reduce the effect of forces delivered through the jaw or face, or to reduce brain rotation, is limited..$^{3464}$ If the helmet's padding material is able to reduce the total force acting on the head, then the tangential component causing head rotation will also be reduced..$^{34-36}$ However, for blows delivered to the region of the jaw or face, or blows on the chest or back, the hockey helmet is not effective in reducing rotational effects. ${ }^{34} 36445$

Therefore sports organisations should consider alternative strategies to reduce the risk of mTBI. Firstly, they should

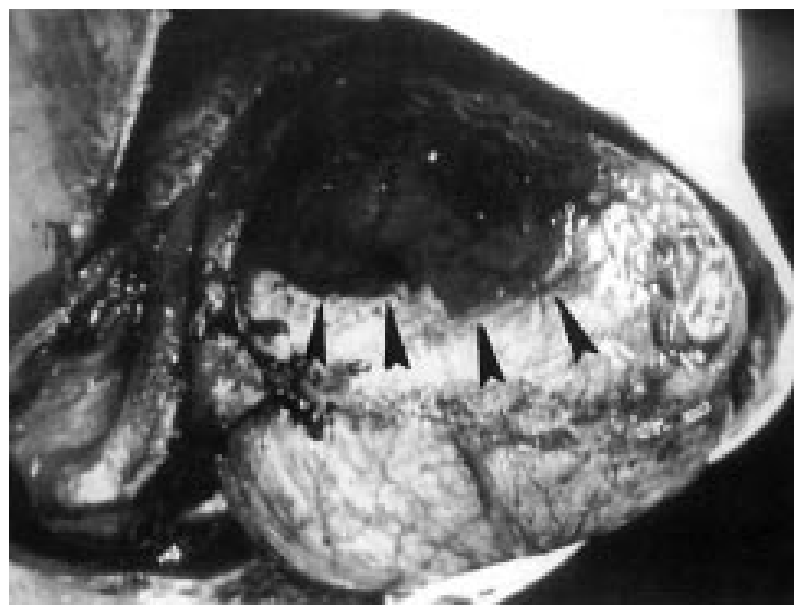

Figure 8 Acute epidural haematoma after a stick injury to the temporal region of the skull. The bone in this region of the skull is very thin. The 12 year old player died four hours later.' 


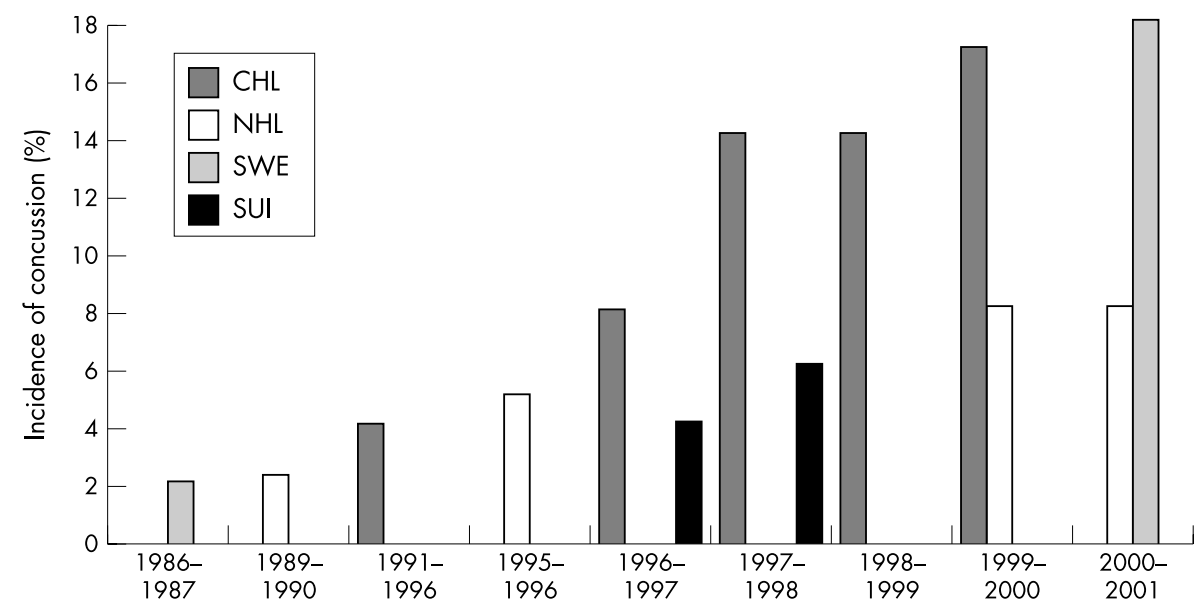

Figure 9 Incidence of concussion (mTBI) from 1986 to 2001 in Sweden, Canada, North America, and Switzerland. ${ }^{7} 1843$ CHL, Canadian Hockey League, 1991-200; NHL, National Hockey League, 1989-2001; SWE, Swedish Ice Hockey League, 1986-2001; SUI, Swiss Ice Hockey League, 1996-1998.

eliminate head checking with any part of the body-for instance the elbow or shoulder (fig 13).

For this reason, the rules committee of the International Ice Hockey Federation IIHF proposed in 2001 a new rule to eliminate every "clean" check to the head. This new rule will be mandatory worldwide from July 2002 by the national associations under the regulation of the IIHF (New Rule 540 IIHF: Checking to the Head and Neck Area). This means that every contact to the head with the body, elbow, shoulder, knee, or stick of an opposing player will be penalised more severely (Minor Penalty/Major Penalty plus automatic Game Misconduct or Match Penalty) at the discretion of the referee in the same progression of the penalty as laid out in the checking from behind rule (Rule 523 IIHF)..$^{50}$

Secondly, sports organisations have to make mandatory the use of an internal mouthguard, which may not only prevent dental and orofacial injuries, but also play a role in the reduction of incidence and severity of mTBI. ${ }^{51}$

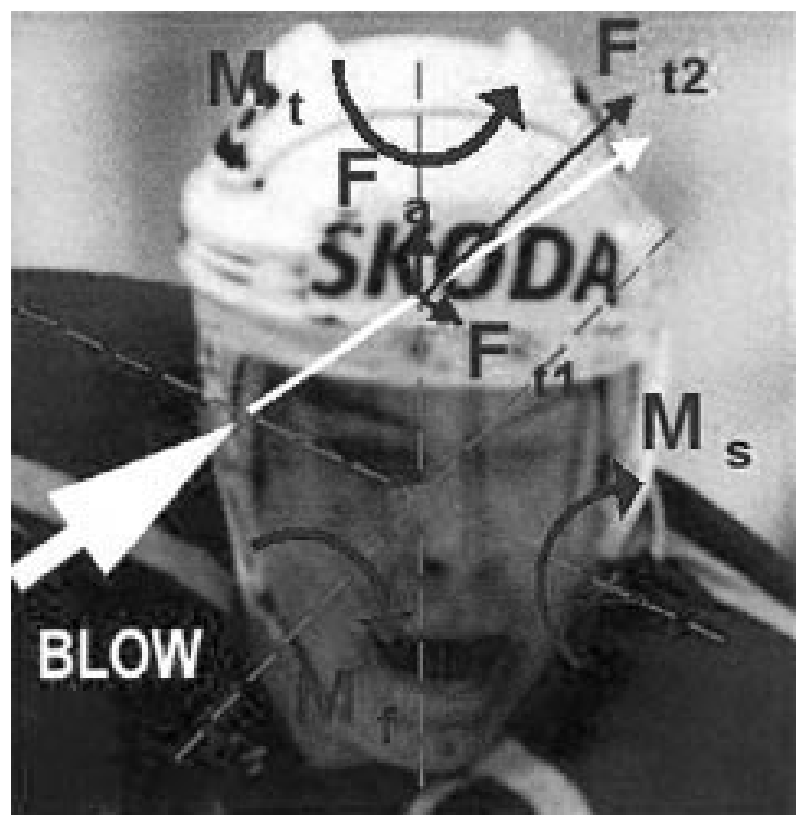

Figure 10 Direct eccentric blow to the head. Protective headgear, with its padding, helps to reduce the effect of the final force $\mathrm{F}$ and therefore may reduce the risk of a focal head injury. $M_{t}$, moving force in the transversal plane; $M_{t}$, moving force in the frontal plane; $F_{1}$, force in the transversal plane; $F_{12}$, force 2 in the transversal plane; $F_{a}$, force in the axial plane.

\section{Eye injuries}

Since the introduction of the mandatory use of a full facemask in 1978, the pattern of injury has changed. Most ice hockey injuries before the use of a full facemask were found above the shoulder, most of them being lacerations. ${ }^{2}$ The reduction in ocular and facial trauma has certainly been impressive. The consequences of these changes show that blinding injuries are virtually non-existent when approved full facemasks are used. ${ }^{48}$ Soft tissue injuries around the face and mouth, primarily lacerations and contusions, also decreased significantly from $38 \%$ of players to about $9 \%$ a year from 1975 to 1988. ${ }^{2}$ It has also been reported by Pashby, ${ }^{28}$ that properly fitted visors are as effective as full facemasks in the prevention of severe ocular injury, and they also decreased laceration by about $58 \%{ }^{28}$ However, the problem of eye injury persists. Eye injuries are still being documented in all players, primarily older ones, but always those not wearing eye protection. From 1972 to 2002, the Canadian Ophthalmological Society (COS) registered 1914 eye injuries in ice hockey, with 311 cases of blindness (fig 14). ${ }^{28}$

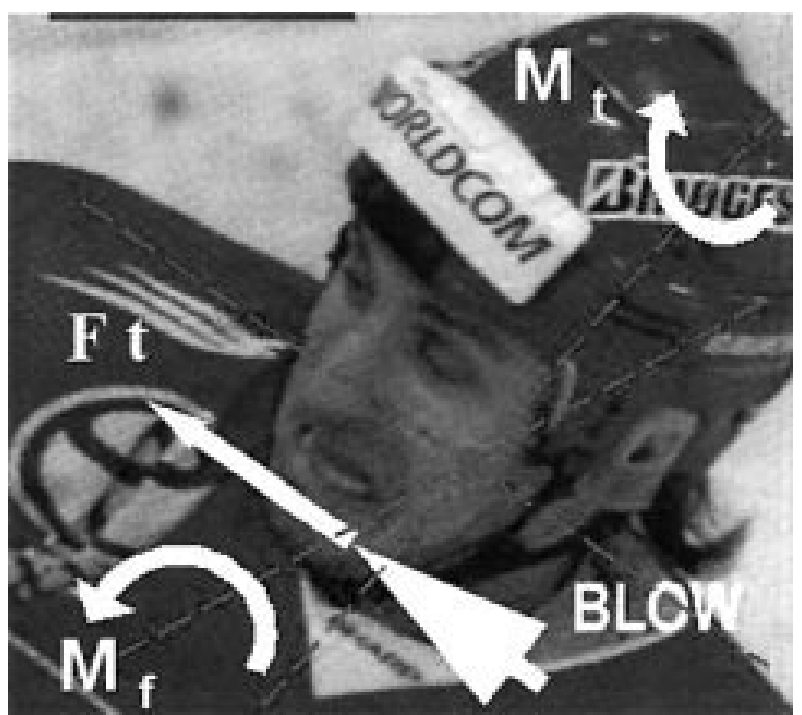

Figure 11 Direct blow to the face or jaw. No protective equipment, such as helmets and mouthguards, is effective in reducing rotatory components. $M_{t}$, moving force in the transversal plane; $M_{t}$ moving force in the frontal plane; $F_{t}$, force in the transversal plane. 


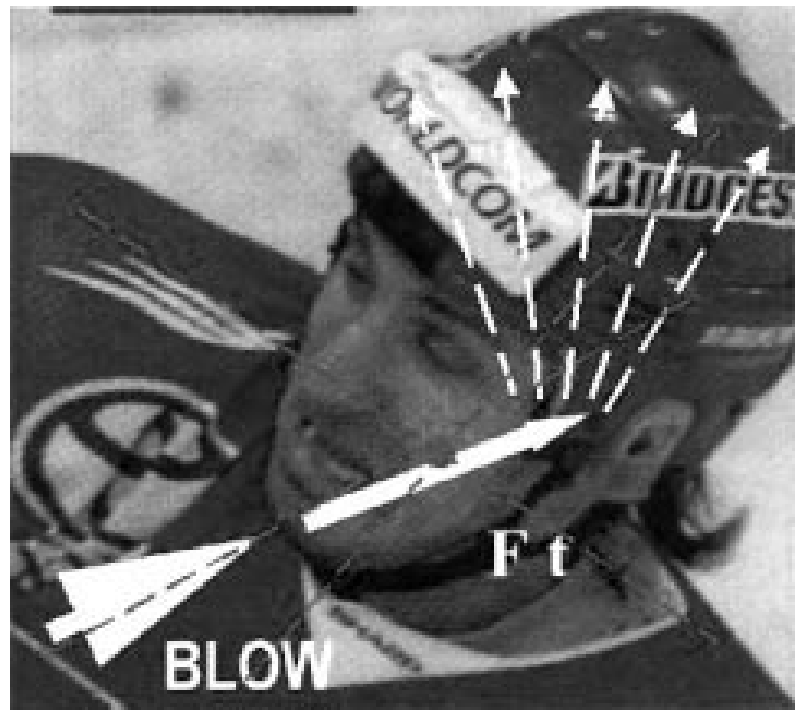

Figure 12 Blow directed to the chin. A mouthguard may have the ability to absorb the impact loading from the chin and to distribute the remaining energy, through the resilience of the material combined with its design, over a much larger surface area, thereby reducing the final force on the brain. $F_{t}$, force in the transversal plane.

The major decrease in the number of eye injuries was first noticed after the introduction of the new rule in $1975 .{ }^{52}$ However, soon after the mandatory use of certified full facemasks for juniors in 1978, the number of blinding injuries started to increase. This may be because these injuries occurred in older players who were not wearing face protection. None of the blinding injuries were suffered by players wearing a certified full facemask. ${ }^{28}$ Over the last few years, nine players (eight in Canada and one in Sweden) have received blinding injuries when wearing a visor. ${ }^{28}$ Tegner and Pashby analysed these injuries using video recordings. All these players were not wearing the visor correctly; these injuries would not have occurred if they had been (fig 15). ${ }^{28}$

The controversy over the use of a full facemask and a visor was first analysed by Clayton in a study of the Quebec Major Junior Hockey League during the seasons 1991-1992. ${ }^{53}$ This study compared the number of neck, head, and face injuries incurred while wearing a full facemask versus visor. The results showed that the eye injury rate was triple that when a visor was worn instead of a full facemask..$^{53}$ On the other hand, head injury rate fell dramatically when this change was implemented, and neck injury rate as well as face and jaw injury rates were halved (fig 16). ${ }^{53}$

In contrast with these findings were the results of Benson et al, ${ }^{54}$ who conducted a prospective study during the 1997-1998

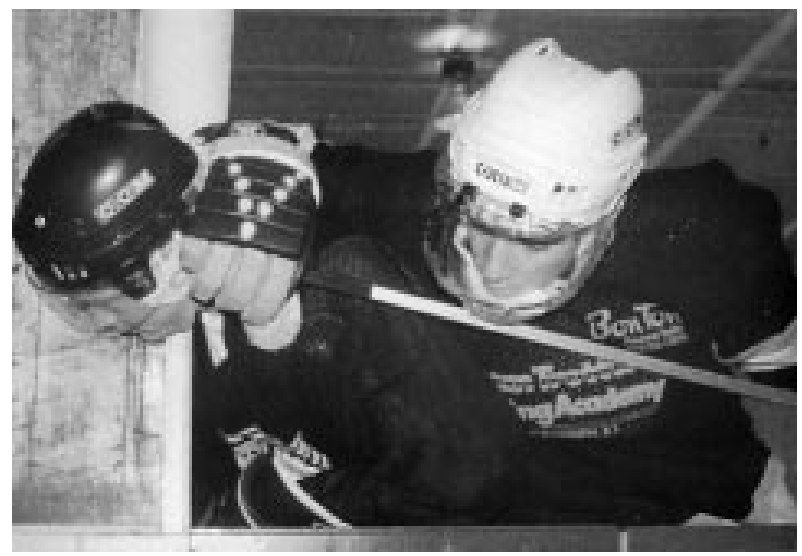

Figure 13 A head check against the glass can generate a sudden acceleration-deceleration of the brain, which can result in a mTBI. ${ }^{35-38} 44$
Canadian Inter-University Athletics Union (CIAU) hockey season and compared the risk of sustaining a head or neck injury by the wearing of full facemasks or visors. ${ }^{54}$ The Ontario Universities Athletic Association required that all athletes under its jurisdiction wore full facemasks for every practice and game. In contrast, the Canada West Universities Athletic Association required all athletes to wear, as a minimum, visors, for every practice and game. The results of this study showed that the risk of sustaining a facial laceration was 2.3 times greater for players wearing a visor than for those wearing a full facemask. Mostly lips and eyebrows were lacerated. These findings may be explained by incorrecting wearing of the visors and helmets. In fact, too many players wear visors incorrectly, in order to obtain a clearer view, and wear helmets with a loosened chinstrap. These two possible risk factors of wearing the protective equipment incorrectly were not analysed by Benson et al. ${ }^{54}$ In a prospective study of the Swiss Ice Hockey Leagues A and B 1996-1998, we reviewed the causes of head and face injuries and we analysed the correctness of wearing visors and helmets. ${ }^{95}$ Similarly to other studies, we found that lacerations, at 55\%, were the most common head and face injuries, ${ }^{95-65}$ followed by fractures (23\%), mTBI $(17 \%)$, and eye injuries $(8 \%) .^{95}$ Facial lacerations were recorded mainly in the forehead region. ${ }^{955659}$ In three quarters of the cases, the players were not wearing a visor or a full facemask at all, and in the remainder the players were wearing the visors incorrectly. All eye injuries occurred in players not wearing a visor or full facemask at all. ${ }^{95}$ None of these injuries would have happened if the players had been wearing at least visors, and if the visors and helmets had been worn correctly. ${ }^{55}$

Benson $e a^{53}$ further reported that stick contact with the face was the predominant mechanism of the lacerations. The incidence of chin lacerations was higher among players wearing a full facemask than those wearing a visor. ${ }^{53}$ Contact with an opponent or stick by body checks or collisions caused the majority of lacerations in athletes wearing a full facemask. ${ }^{53}$ These findings may also be explained by the incorrect wearing of helmets with loosened chinstraps. ${ }^{55}$ In fact, when a force is directed to the face, the helmet can ride back on the forehead allowing the stick to slide under the visor or full facemask and lacerate the eyes or face, even if the equipment is worn correctly (fig 17)..$^{55}$

The rules of the IIHF allow wearing of helmets only with a properly fastened chinstrap. ${ }^{52}$ Incorrect fitting or misuse of helmets with single straps could result in increased movement of the helmet during collisions. ${ }^{56}$ LaPrade and Broxterman ${ }^{56}$ asserted that, even when properly worn, the single strap helmet fixation system does not secure the helmet efficiently to the head. Pashby ${ }^{28}$ came to the same conclusions. They both recommended the use of a double chinstrap to prevent the helmet from riding back on the head during a collision. Unfortunately, double chinstraps are not so acceptable to the players, and even the ice hockey organisations do not mandate their use. Further studies are necessary.

There is a tendency in modern ice hockey for a more aggressive playing style. The players today are bigger, faster, and stronger, which increases the energy involved in collisions thereby increasing the likely rate of injury. We showed in a prospective study of the Swiss Ice Hockey leagues A and B a direct correlation between players violating the rules and head and facial injuries. Head and facial injuries were caused by illegal activity in most cases. ${ }^{9}$ Benson et $a l^{53}$ found that over $40 \%$ of facial injuries in players wearing a visor were caused by an illegal action. Stick contact with the face was also a predominant mechanism. Pettersson and Lorentzon ${ }^{57}$ found that $57 \%$ of facial lacerations were caused by an opponent's stick and that most of these stick injuries were caused by illegal play. Many other studies confirm these observations. ${ }^{1} 91015182526455558-60646667$

In contrast with the opinion of referees, the reporting doctors considered that most head and facial injuries were caused 


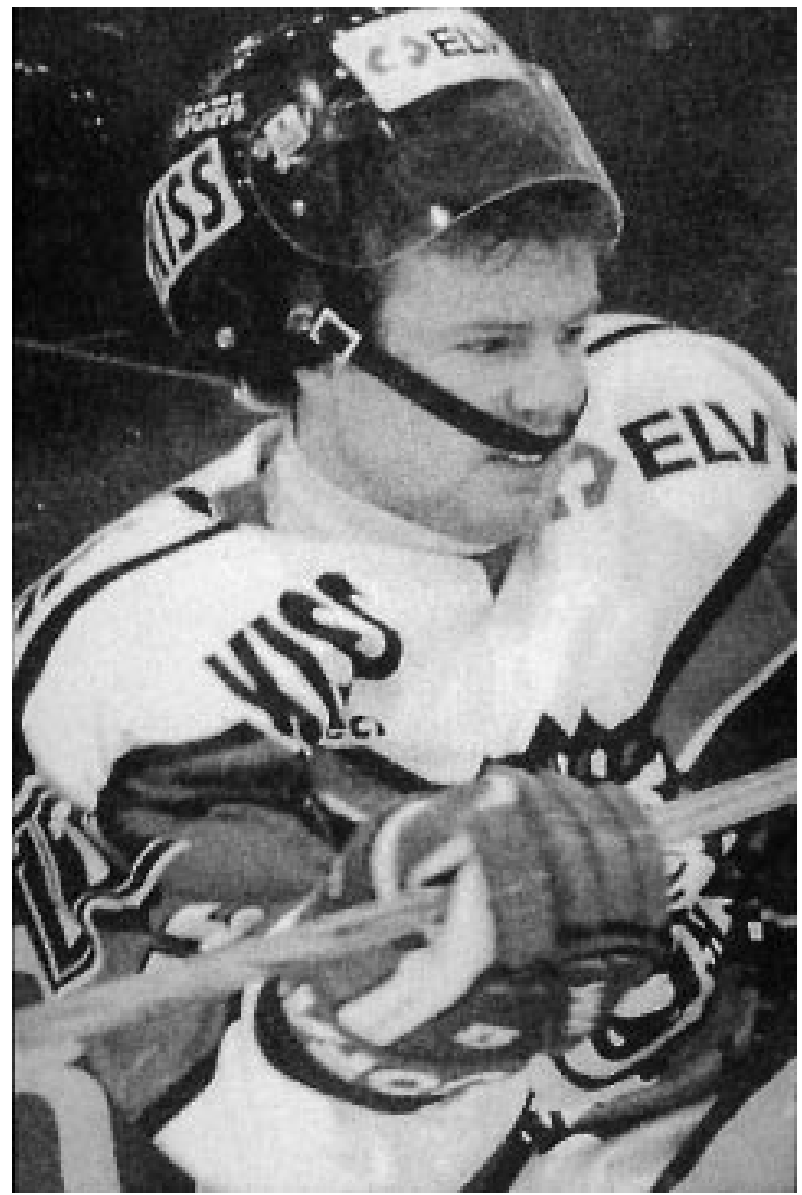

Figure 15 Incorrect way to wear a visor. The loosened chinstrap allows the helmet to ride back on the head when a force is directed to the frontal region and allows the stick to slide under the facemask and lacerate the eye or forehead region.

by illegal activities. It is alarming that the referees in most of these instances of potentially serious face and head injuries did not call a penalty. Our prospective study on the Swiss Ice Hockey leagues A and B showed that $56 \%$ of head injuries and $46 \%$ of facial injuries were caused by illegal activity with the stick as judged by the reporting doctors. ${ }^{9}$ Of these illegal activities, only $29 \%$ were called a penalty by the referee. ${ }^{9}$ There are many studies world wide showing that most of these injuries occurred during on-ice events that were not penalised at all. $^{26545636467}$ Besides stricter enforcement of the rules, changes in the attitudes of hockey officials are needed. When rules are not enforced regularly, they are seldom obeyed, and the formal control system-that is, the referee-becomes merely symbolic. ${ }^{68}$

The increased protection of the face through the compulsory wearing of helmets with full face protection, which was introduced in 1975, appears to have led to a more aggressive playing style perhaps because it is believed that the head, face, and throat are now at less risk. Many believe that, after the mandatory use of helmets with a full facemask, players developed a false sense of security and invincibility leading to excessive risk taking behaviour with a resultant increase in illegal and injurious activity. ${ }^{2} 9151722232635404445636970$ It is also interesting that increased high stick violation and the use of the full facemask as a weapon were noted in 1980 by Reynen and Clancy ${ }^{26}$ after mandatory use of the full facemask. In 1988, the American College Hockey Coaches Association meeting came to an anonymous agreement that full facemasks promoted rough and violent play. ${ }^{70}$ They called for approval of a visor type of mask to decrease the violent play. In 1988 and 1992, the US Olympic team used a visor for over nine months, playing a 60 and 80 game schedule against college and NHL teams, and they documented no eye injuries. ${ }^{70}$ Other authors have even speculated that the mandatory use of helmets with full facemasks has increased the risk of neck injuries and mTBI. ${ }^{54}{ }^{67}{ }^{67}$ Benson $e t ~ a l^{54}$ found no statistically significant risk differences for neck injuries and mTBI for players wearing visors versus full facemasks. Stuart et $a l^{67}$ recently investigated, in a prospective cohort observational study of the United States Hockey League Junior A, the relation between injuries and type of facial protection, and determined whether full or partial facial protection was associated with an increased incidence of mTBI, eye injuries, and neck injuries. This is the only epidemiological ice hockey study to accurately control for individual exposure time and examine vulnerability to injury based solely on the facial protection afforded. Junior A hockey players were between 16 and 21 years of age. Full facemasks were mandatory for all players younger than 18 , and players 18 years and older were free to choose no facial protection, visor, or full facemask. No significant differences in the risk of neck injuries or mTBI based on the type of facial protection worn were found. It was also found that the risk of an eye injury was 4.7 times greater for players wearing no

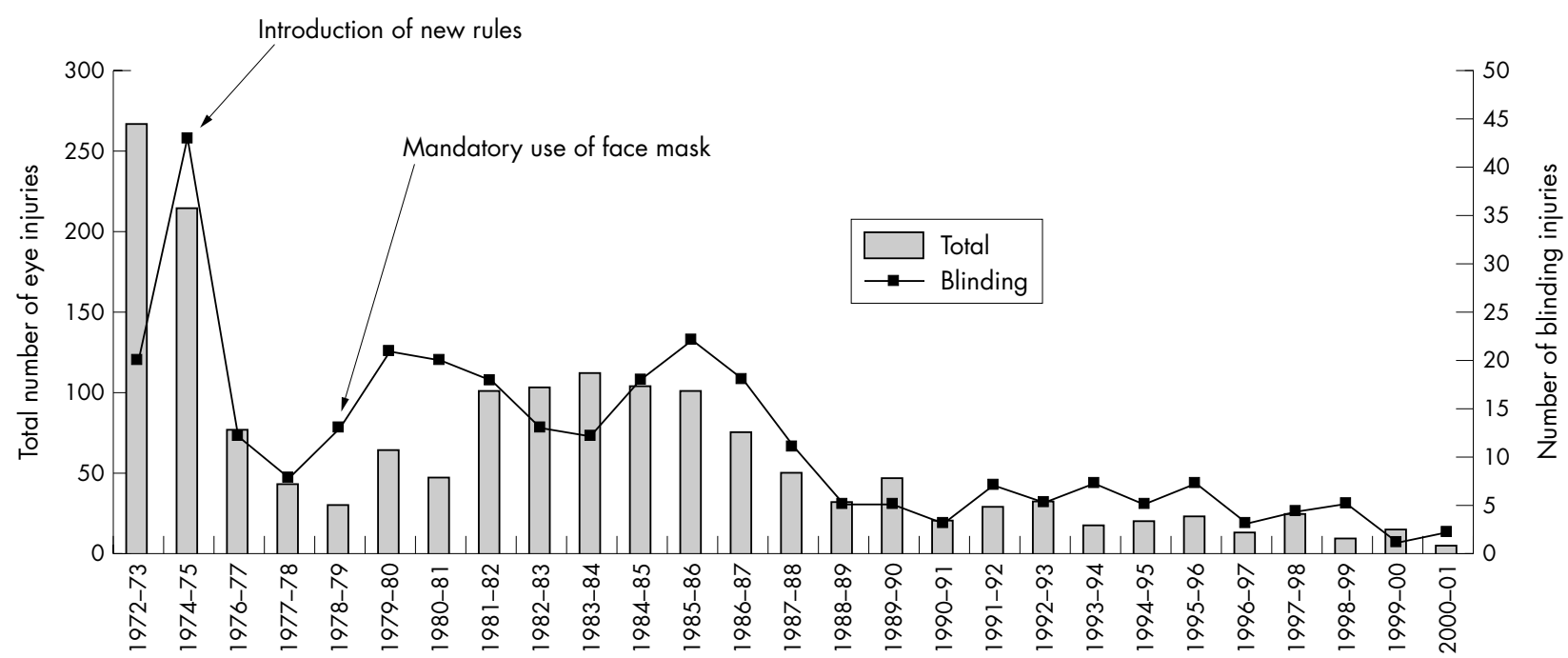

Figure 14 Canadian Ophthalmological Society survey of eye injuries from 1972 to 2002. The introduction of high sticking and hooking penalties in 1975 and the mandatory use of certified full facemasks in 1978 is indicated. ${ }^{28}$ 


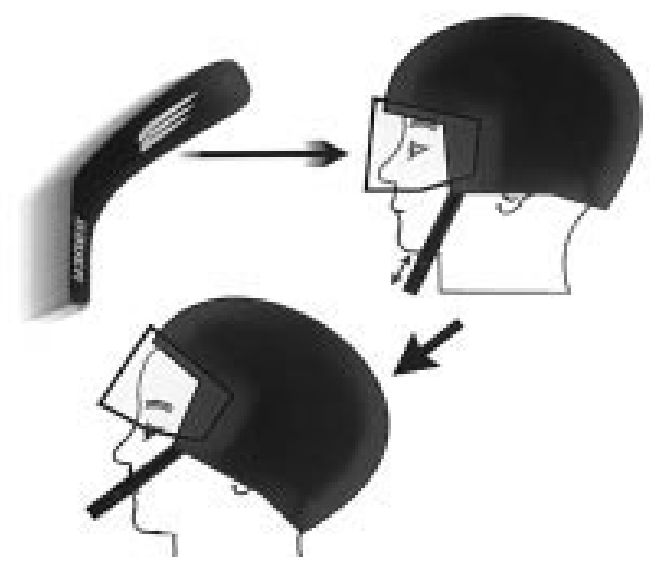

Figure 17 The visor is correctly fixed to the helmet, but the helmet is attached with a loosened chinstrap. This allows the stick or puck to slide directly under the visor. There is also no longer any padding effect of the helmet, which may help to reduce the forces to brain and maybe the risk and severity of an $\mathrm{mTBl} .{ }^{55}$ The same mechanism can occur if a full facemask is worn with a loosened chinstrap.

facial protection than for those wearing partial protection. No eye injuries occurred in players wearing full protection.

As a full facemask may tend to encourage aggressive play and a feeling of invincibility in young players, and as senior and professional players never play with full facemasks, compromises have to be found. For these reasons, we have proposed the use of helmets with visors, as approved by the standard organisations, and enforcement of the correct way to wear them. It may therefore be expected that the number of severe head injuries, primarily the avoidable eye injuries and the periorbital skin lacerations, will be reduced through the correct use of helmets and visor. One cannot expect all head and face injuries to cease. A further decrease in all kinds of severe head and face injuries can only be achieved by better education of the players and strict enforcement of the rules. It would appear that the penalties that most leagues administer for high sticks and slashing, which make contact with the opponent, have not been enough to deter violent stick work. Many authors recommend that a high sticking or violent slashing penalty should be the same as for checking from behind: removal from the present game and suspension from the next game. ${ }^{68}$ This is a critical point, because, if the ice hockey organisations make rules that are too strong, the referees will not enforce them. We therefore need to devise rules that referees are willing to endorse, otherwise they will not enhance the safety of the players.

\section{Spinal injuries}

After head injuries, neck injuries are considered the most catastrophic. American football has been considered the most dangerous sport for causing such spinal injuries. Approximately 819 deaths were directly caused by football from 1931 to 1986 , with a peak incidence of 3.4 deaths per 100000 players in 1968. ${ }^{71}$ The National Football Head and Neck Injury Registry System was then developed to register and review these data. ${ }^{71}$ American football is a typical example of a sport, in which the consequences of the introduction of new rules and their strict endorsement had dramatic effects on the incidence of spinal cord injuries. After the introduction of new rules in 1976-that is, prohibition of head impact in blocking, tackling, and head butting - and helmet standards, the incidence of death fell to approximately 0.5 per 100000 players in 1978, and the number of spinal cord injuries rapidly decreased as well. ${ }^{71}$ Rule changes have played an important role in reducing fatalities. Using Torg's data from 1976 to 1987 and Mueller's data from 1988 to 1993, a summary of the incidence of cervical quadriplegia in high school and college football is shown in fig $18 .^{71} 72$

There is no doubt that this 1976 rule change has made a major contribution to the reduction in deaths from head and cervical spine injuries. Data collection has also played an important role in the prevention of football injuries. The American Football Coaches Association has encouraged the tracking of football fatalities annually since 1931. There is no question that the beneficial changes are the result of reliable data collection and the publication of the results in the athletic and medical literature. Persistent surveillance of sports injury data is vital if progress is to continue in the prevention of fatalities. To help offset the trend of increasing head and neck injuries and fatalities in American football, the National Operating Committee for Safety in Athletic Equipment (NOCSAF) was founded in 1969 to establish safety standards for athletic equipment. In football also, initial efforts were directed to head protection. A safety standard for football helmets was achieved in 1973, and the first helmets were tested on the NOCSAE Standard in 1974. It was then made mandatory for all students in college (in 1978) and high school (in 1980 ) to wear NOCSAE certified helmets. ${ }^{22}$ The education of coaches and correct tackling techniques being taught by coaches have also played an important role in decreasing the number of head and cervical spine fatalities. ${ }^{22}$ Improved protective equipment has also been purchased and more time

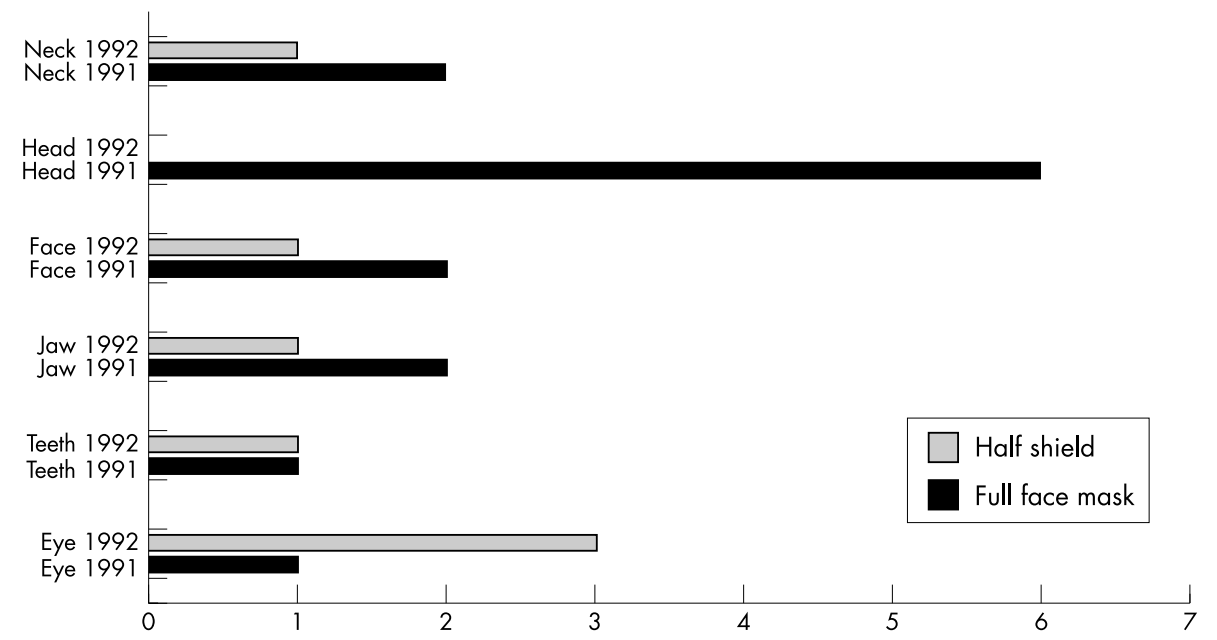

Figure 16 Relation of head and facial injuries by the wearing full facemasks (season 1991) or visors (season 1992) in the Quebec Major Junior Hockey League. ${ }^{53}$ 


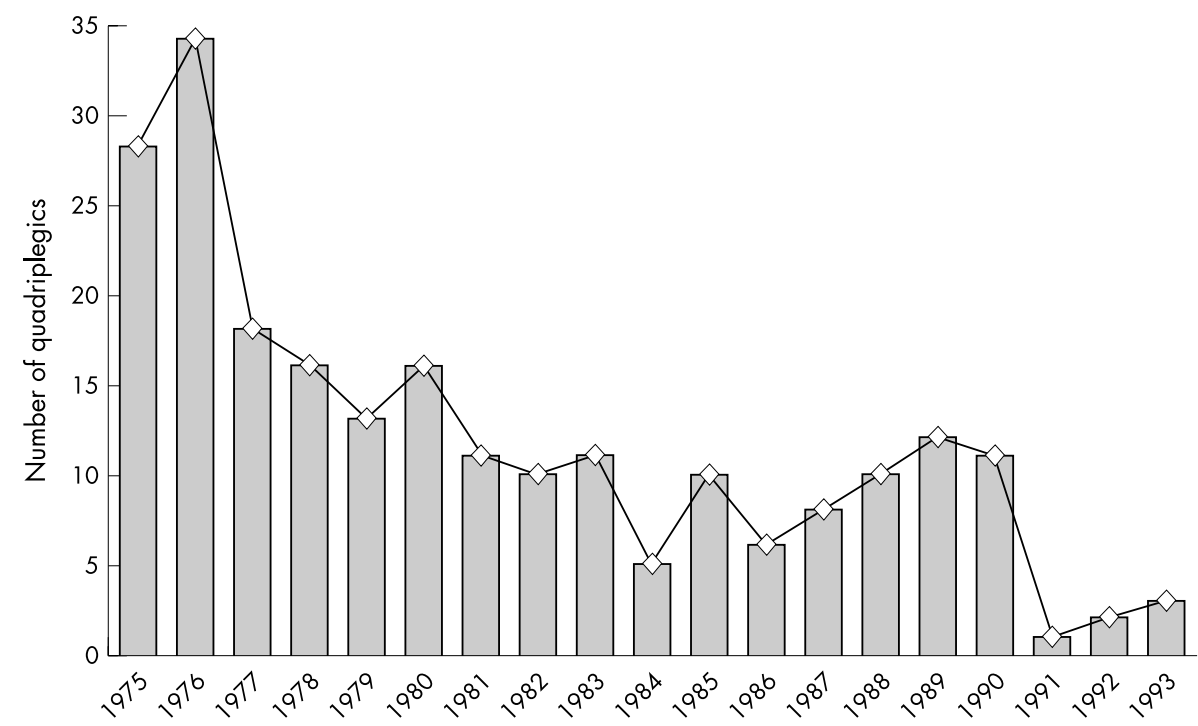

Figure 18 Implementation of American football rule changes in 1976 prohibiting the use of the head as the initial point of contact resulted in a steady decline in quadriplegia at the high school and college level. ${ }^{71} 72$

spent in fitting the equipment. Helmet manufacturers have also stressed the importance of a proper fit to help to reduce head injuries. ${ }^{22}$ Because of the large number of participants in American football, this sport still has the greatest number of catastrophic injuries a year.

However, football is not the only sport that causes spinal injuries. Charles Tator and SportSmart Canada began in the early 1980s to draw attention to cervical spine injuries in ice hockey. In the English literature, there were no cervical spinal cord injuries attributed to ice hockey reported..$^{22-25}{ }^{71}{ }^{73}$ A review of the records of two major hospitals in Toronto found no ice hockey spinal injuries between the years 1948 and 1973. Between 1974 and 1981, six cases were seen at these hospitals. In 1981 this led to the formation of a committee on the prevention of spinal cord injuries in ice hockey. ${ }^{22-25}$ Questionnaires were sent to specialists throughout Canada, including neurosurgeons, orthopaedic surgeons, and physical medicine and rehabilitation specialists. ${ }^{22-25}$ Major spinal injuries (injury with neurological deficits due to spinal injury and any fracture or dislocation of the spine with or without permanent neurological deficits) were rare in ice hockey in the 1960s and 1970s. s2-25 $^{73}$ The SportSmart data showed that there were 286 spinal injuries from 1982 to 1996, including many cases from the United States and Europe, but beginning in 1980, the annual incidence increased considerably. From 1981 to 1996 there was an average of 17 cases a year, with a maximum of 26 injuries in 1995..$^{22-25} 73$ The incidence of severe spinal injury with paralysis in 1994 was about three times greater in Canadian hockey than in American football. ${ }^{71}$ Between 1994 and 1996, there were 53 spinal injuries.

At the beginning of this survey, the players were injured during illegal play, in particular pushing or checking from behind (59.8\% in 1966-1987). ${ }^{22-73}$ As a result of the data made available by this survey, the CAHA introduced in 1985 specific rules against pushing or checking from behind. ${ }^{73}$ These rules were then also introduced, through the support of Dr Pietro Segantini, a past member of the rules committee of the International Ice Hockey Federation (IIHF), in 1994 into the IIHF rules books (Rule 606 "Charging and Checking from behind").${ }^{74} \mathrm{~A}$ few years later, an international network of doctors realised that it was necessary to register all known spinal injuries in the world. An International Committee of Spinal Injuries in Ice Hockey was then formed in 1997 under the chairmanship of Professor Tator with members from Sweden, Finland, Switzerland, United States, and Canada. During the Eighth International Symposium of the IIHF on Medicine and
Science in Ice Hockey in May 1998 at the University Hospital Zurich-Balgrist, Switzerland, an endorsement of the IIHF was obtained in order to secure doctor contacts in each of its 56 member nations. ${ }^{23}$

Charles Tator presented the recent results of the SportSmart registry during the 2001 meeting of NHL doctors in Toronto. For the years 1966 to 1999, the SportSmart registered world wide 401 major spinal injuries (fig 19). ${ }^{25}$ Eight players were known to have died as a result of their injuries ${ }^{25}$

More than 300 major spinal injuries were adequately documented. ${ }^{22-25}$ The average age of the players was 18 years (46\% were 16-20 years). A spinal cord injury was documented in $53 \%$ of the cases, and there were $22 \%$ spinal injuries with quadriplegia. This recent data suggest that preventive strategies and the introduction of a specific rule against hitting from behind have been effective in decreasing the number of severe spinal injuries. ${ }^{74}$ Checking from behind now causes "only" $25 \%$ of the spinal injuries. ${ }^{25}$

Several causative factors have been discussed, such as increased aggressiveness and willingness to take risks, a feeling of invincibility, and the lack of awareness of the possibility of a spinal cord injury in ice hockey. ${ }^{73}$ Many coaches have also not instructed their players about the risk of a spinal injury and the methods of protecting themselves. ${ }^{24}$

Biomechanical research by Bishop et a ${ }^{75} 76$ showed that the greatest axial forces were applied to the cervical spine in slight flexion. This position of injuries was consistent with actual injury situations in hockey and football. Approximately two thirds of players with cervical spine injuries wore full facemasks and all wore helmets. ${ }^{22-25}$ Further research by Bishop and Wells ${ }^{77}$ found that the padding in the helmet adequately decelerated the head on impact; however, the neck itself had to decelerate the torso. They found that impact velocities as low as $1.8 \mathrm{~m} / \mathrm{s}$ provided compressive loads from C3 through C5 to $75 \%$ of their failure loads in axial compression. ${ }^{77} \mathrm{Sim}$ and $\mathrm{Chao}^{78}$ have shown skating speeds of $9.4-12.2 \mathrm{~m} / \mathrm{s}$ and the speed of a sliding skater on ice is approximately $6.7 \mathrm{~m} / \mathrm{s}^{78}$ Both situations are certainly well above the $75 \%$ loads applied by Bishop and Wells. ${ }^{77}$ Another investigation by Bishop et $a l^{76}$ dealt with the mechanical effect of the helmet and full facemask. There were speculations that the full facemask and helmet may shift the centre of the head mask anteriorly enough to result in flexion of the head on impact. Their studies showed that there did indeed seem to be a slight increase in the centre of the mask anteriorly and increased inertia of the head form, but it was believed to be quite small and thought not to contribute to injury. ${ }^{76}$ 


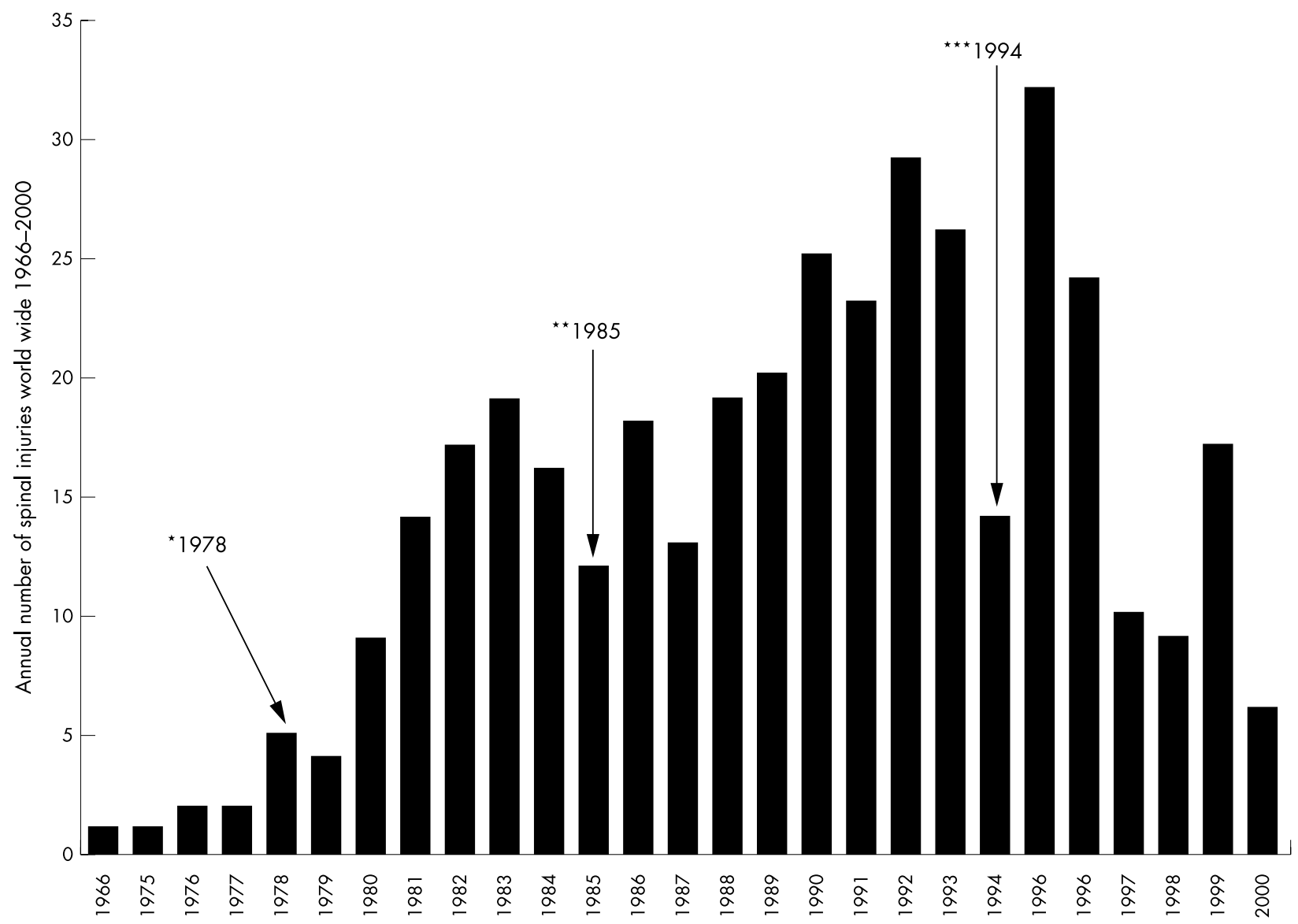

Figure 19 Total number of major spinal injuries world wide from 1966 to 1999 in ice hockey. ${ }^{*} 1978$, Mandatory wearing of full facemask by junior players; ${ }^{* *} 1985$, new checking rules $\mathrm{CAHA} ;{ }^{* * *} 1994$, new checking from behind rules, IIHF. ${ }^{22-25} 74$

\section{Dental injuries and use of a mouthguard}

This review of the epidemiology of orofacial sports related injuries presents and assesses only scientific databases within the past 10 years. To our knowledge, the Eighth International Symposium of the IIHF on Medicine and Science in Ice Hockey in May 1998 was the first to deal with dental problems in ice hockey.

Piccininni ${ }^{79}$ suggested categorising dental injuries in ice hockey in the following way: A, soft tissue injuries; B, dental injuries; C, bony injuries; D, other injuries.

(A) Soft tissue injuries: these would include contusions or lacerations to the lips, tongue, or gingiva, as well as dislocations or trauma to the temporomandibular joint, bruising to the facial muscles, nerves, fascia, and blood vessels.

(B) Dental injuries: chips or minor fractures in the outer edentulous layer, moderate fractures that involve the underlying dentin layer, and severe fractures that result in exposure of the pulp or nerve of the tooth. This group include situations where a tooth is luxated (moved out of its normal position), intruded (repositioned inward into the alveolus), or avulsed (knocked completely out of the socket). A tooth concussion, where the tooth is traumatised but not moved out of position, can also be a serious injury. Trauma to the periodontal ligaments supporting the tooth in the alveolar socket can be placed in this category.

(C) Bony injuries: minor fractures to the alveolar bone surrounding a particular tooth or group of teeth as well as fractures to the facial bones. These are especially important in the maxilla or mandible, including fractures in the ramus or condyle of the mandible.

(D) Other injuries: these may include aspiration of teeth or other dental prostheses, and cerebral concussion resulting from an upward blow to the jaw that caused the teeth to meet violently or the condyle of the mandible to be driven into the fossa of the temporal bone.

To date, only a few epidemiological studies on dental injuries in ice hockey have been published. In a six year study in Finland, Sane ${ }^{80}$ reported, in 1988, $11.5 \%$ of all ice hockey injuries as maxillofacial and dental injuries, which represented up to $38 \%$ of the costs of all injuries. Morrow et al ${ }^{81}$ conducted in 1991 a survey in 626 high schools with college and university athletes and noticed that the highest rates of orofacial injury were in basketball $(10 \%)$ followed by ice hockey in $9.8 \%$. Of the traditional sports, $64.1 \%$ of the injuries to the teeth occurred during participation in basketball, baseball, and ice hockey. Kujaya ${ }^{82}$ suggested in 1995 that dental injuries comprised over $32 \%$ of all ice hockey injuries in a four year study of Finnish sports, and a survey in 2000 reported that the sports receiving the most orofacial injuries were baseball and biking, followed by ice hockey and basketball. ${ }^{83}$ Piccininni ${ }^{79}$ showed that most dental injuries were caused by the stick $(75 \%)$.

However, most of the literature on dental injuries and mouth protection comes from contact sports such as American football, rugby, baseball, and field hockey. Very early studies indicated that mouthguards may help to decrease the number of mouth injuries in competitive sport such as American football. Stenger et al ${ }^{84}$ reported that initially dental and mouth injuries were almost $50 \%$ of all football injuries, and that with the introduction of full facemasks this number was reduced to almost half, and with the addition of mouthguards the number of dental injuries decreased to $1.4 \%$. Stenger et al also claimed that mouthguards reduced mTBI and neck injuries during a five year study of Notre Dame University football 
team. They showed that, with a mouthguard in place, there was an altered mandibular position on lateral skull radiographs so that the condyles were distracted from their fossae. They postulated that forces from mandibular impact applied to the head and neck would be attenuated resulting in fewer injuries. Their views are, however, speculative.

In 1967, Hickey et a ${ }^{85}$ determined the effect of mouth protectors on pressure changes and bone deformation within the skull in a cadaver model. Using an intracranial pressure transducer, they showed that mouthguards reduced both intracranial pressure and bone deformation by about $50 \%$ after a blow to the chin.

Chapman $^{86}$ described two basic possible impact directions on the mandible that generate distinct acceleration forces on the skull: a blow on the inferior and anterior aspect of the mandible. A blow received on the inferior aspect of the mandible is transmitted through the midfacial skeleton, forcing the skull to rotate backwards about an axis passing roughly through the mastoid processes. He proposed that a mouthguard could act by absorbing some of this impact, when the mandibular teeth close on its occlusal surface. Therefore the rotation effect of the impact on the skull would be considerable lessened. In the case of an impact delivered to the anterior aspect of the mandible, the head and neck would be displaced posteriorly along the line of the force causing linear acceleration of the brain. He showed, on radiographs of the skull, that a bimaxillary mouthguard can separate the elements of the temporomandibular joint and therefore reduce transmission to the base of the skull from the impact on the chin.

Porter and $\mathrm{O}^{\prime} \mathrm{Brien}^{87}$ suggested a third potential effect of the bimaxillary mouthguard when the force is directed to the lateral side of the mandible causing the head to rotate about an axis passing vertically through the odontoid process. They suggested that the resilience of the material from which the bimaxillary mouthguard is made, combined with its design, could absorb some of this force by deformation of the mouthguard. They also suggested that the ability of the mouthguard to attenuate any impact depends on the absorption of some of the energy by the material at the impact side and that the remaining energy is distributed throughout the mouthguard over a much larger surface area. All this is, however, speculative.

However, already in the early 1970s, when further studies confirmed the earlier findings on the high incidence of injury to the oral region, the AHAUS began to promote and mandate the use of either external or internal mouthguards for younger players. ${ }^{449}$ This mouthguard mandate was adopted by a number of leagues, including the NCAA, but there appeared to be wide variation in both enforcement and type of guard chosen. Sweden has also required the mandatory use of extraoral teeth protectors for junior and boy's team since 1970. Since the compulsory use of face protectors for junior and boy's team from 1978, extraoral teeth protectors are no longer required.

Enforcement of the mouthguard rule in US College hockey was found to be difficult. The lack of knowledge about mouthguards by players, coaches, and team trainers was largely responsible for this. Players believed that uncomfortable, ill fitting protective equipment seriously compromised their ability to perform. Commercial mouthguards were not only uncomfortable because of poor fit, but there was also evidence that they interfered with normal ventilation. Athletes often did not appreciate the importance of mouthguards, and less than $50 \%$ believed that mouthguards prevent injuries. ${ }^{44}$ Coaches were also not totally supportive of mouthguard use, as, in a survey of college football coaches, only $74 \%$ would tell players about a violation. ${ }^{44}$

Athletic mouthguards were first designed to protect the lips and intraoral tissues from bruising and laceration, to protect the teeth from crown fractures, root fractures, luxations, and avulsions, to protect the jaw from fractures, and dislocations, and to provide support for edentulous space (fig 20). ${ }^{5188}$

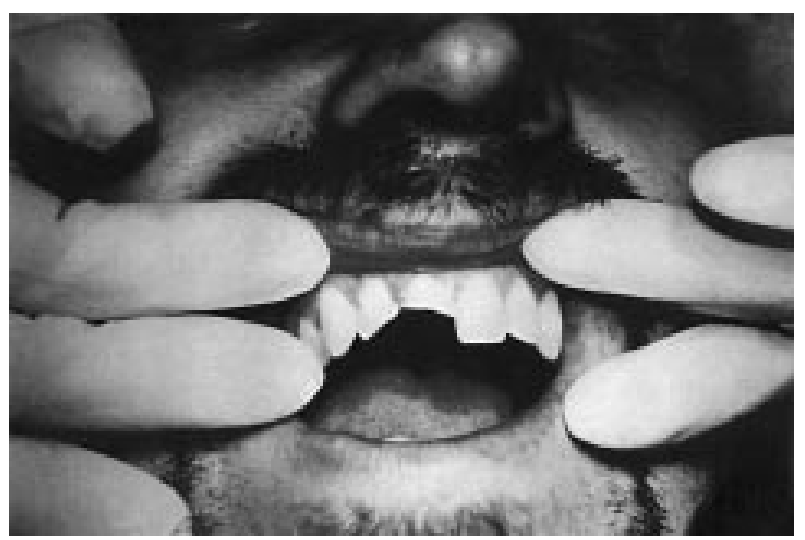

Figure 20 Dental trauma of a junior ice hockey player wearing no face protection and no mouthguard: the opposing player directed an apparently intentional blow with the result of fractures and loss of many teeth. ${ }^{51}$

Although there are no official mouthguard standards, several organisations-for example, ASTM, NCAA, the American Dental Association (ADA), and AHAUS-have offered information based on empirical evidence. ${ }^{88}$ The ASTM (ASTM F697-80) and the CEN (CEN/TC162/WG11 N148) have developed working groups for mouthguard standards to further improve them.

Because many sports related traumatic dental injuries are preventable, the risk to benefit ratio can be increased by the use of appropriate properly fitted protective athletic equipment. At present, mouthguards are recommended in some sports (amateur boxing, football, ice hockey, men's lacrosse, women's field hockey) to reduce both the likelihood and severity of such injuries. ${ }^{88}$ The only professional sport that requires a mouthguard to be worn is boxing. Many enlightened amateur and professional athletes voluntarily wear mouthguards for protection against injuries. More athletes need to recognise the importance of mouthguards for their own personal safety, and coaches, team doctors, and athletic trainers need to be aware of the benefits of mouthguards for the players under their guidance. ${ }^{88}$

Castaldi, ${ }^{44}$ reviewing the history of mouthguards from the early 1930s when they were first used by professional boxers, described how mouthguards protect against injury to teeth, broken jaws, and mTBI. He suggested that custom made mouthguards may not only protect against injuries to the anterior teeth, but may also cushion the force of impact, thus offering protection against jaw fracture and $\mathrm{mTBI}$. Wearing a custom made mouthguard over the lower teeth creates a small gap at the temporomandibular joint and reduces the forces transmitted to the brain from a blow to the jaw or face (fig 21 ).

However, evidence of injury protection by the use of mouthguards is mostly based on case series and retrospective injury surveys. McCrory ${ }^{89}$ stated that the ability of mouthguards to protect against head and spinal injuries in sports falls into the realms of "neuromythology" rather than hard science. He even suggested that there is no convincing evidence to support a protective effect against any type of sporting injuries, because studies with sufficient power have not yet been performed.

Piccininni ${ }^{51}$ suggested that mouthguards alone or in conjunction with additional face protection have been shown to be an effective means of preventing or reducing dental and orofacial injuries. Numerous anecdotal reports have also indicated possible correlation between mouthguards and mTBI. Piccininni focused on two primary mechanisms to explain this correlation. The first was dissipation of forces delivered to the maxilla, skull, and temporomandibular joint complex when the mandible received a blow. The second was stabilisation of 


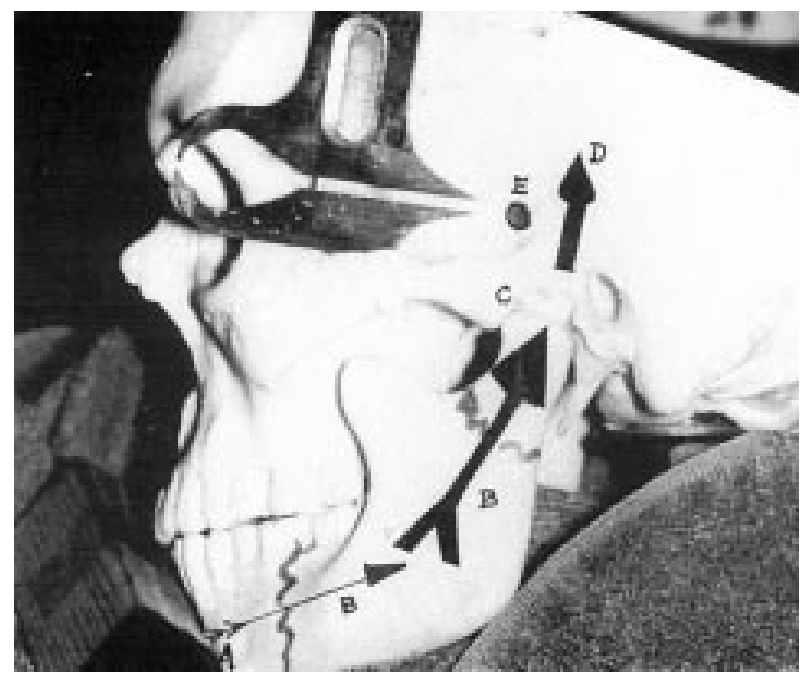

Figure 21 The force of a blow is transmitted from the chin $(A)$ through the lower jaw (B), through the temporomandibular joint at the base of the skull (C), and then to the brain, causing mTBI (D). The thickness gauge reading reveals that the skull in the temple area (E) can be as little as $2-3 \mathrm{~mm}$ thick. Similar types of injury occur in the upper jaw but less commonly. ${ }^{44}$

the skull through increased neck muscle activity when clenching, which may be enhanced with the presence of a mouthguard (fig 22).

Piccininni stated that, for this reason, mouthguards should be promoted as effective devices for prevention of dental and orofacial injuries and that properly designed mouthguards may also play a role in the reduction of incidence or severity of mTBI Barth. et al $l^{90}$ came to the same conclusions. He suggested that the use of properly fitted mouthguards may increase the time and distance involved in acceleration when the mechanism of injury is an upward blow to the head through the mandible.

We think that the minimal cost of properly fitted mouthguards would reap numerous benefits in terms of reducing medical, financial, cognitive, psychological, and social consequences of dental injuries and mTBI. For this reason, the rules committee of the IIHF has proposed that all players participating in the under 20-year category and not wearing a full facemask must wear a custom made mouthguard..$^{50}$ This new rule will be mandatory under the IIHF regulations from July 2002 (New Rule 227 IIHF: Mouthguard). This is the first step in this regard. It is important that this mandate also applies to players wearing a full facemask, because a full facemask cannot reduce the forces transmitted to the brain from a blow to the jaw or chin (fig 23).
This hypothesis seems tenable because properly fitted mouthguards produce a separation between the head of the condyle and the base of the skull. This space supplies the increased distance necessary to reduce acceleration, reducing the force of impact during a blow and thus reducing the impact of those forces on the brain and reducing trauma. ${ }^{90}$

Piccininni further reviewed the types of mouthguard currently being used, which has been proposed by Heintz and completed by Dorney. Today mouthguards can be classified into four types ${ }^{79}$ 91.

- Type I, stock mouthguards: this type offers the least protection and is not acceptable to most athletes (fig 24).

- Type II, mouth formed mouthguards: this type comes in two varieties: shell lined and boil and bite. The latter types come in a wide variety of styles and colours with or without strap attachments. Most of these types are too balky at the periphery or too thin over the critical occlusal table, and are often uncomfortable. They lose up to $99 \%$ of their thickness when fitted (fig 25).

- Type III, custom fabricated mouthguard: this type is made professionally over the dental cast of the athlete's maxillary arch. They are fabricated from a plaster model of teeth using a single layer of material vacuum moulded by a dental office or commercial laboratory. This type has an inconsistent and often minimal thickness across the occlusal surface because of the pressures of the vacuum forming machine. Although this type can be made with or without a strap attachment, a strap may be contraindicated. This type has been popular for several decades. Ethylene vinyl acetate (EVA) material is available in single or double laminated sheets. One product line includes an incisal brace between the two EVA layers. The incisal brace is purported to prevent lingual displacement of the incisors from a traumatic force directed labiolingually (fig 26).

- Type IV, heat and pressure laminated mouthguards: this type has gained popularity in Europe and Australia. The material is better adapted for a more precise fit and retains structural integrity for longer periods of time, compared with all other mouthguards and fabrication techniques. The heat/pressure laminating machine offers the added capability of fusing multiple layers of EVA material to the desired thickness. These multilaminated guards require both upper and lower plaster models to be taken of the athlete. The predicability of material thickness in the critical area is believed to enhance protection and allows articulation of the arches to enhance mandibular stability during impact (fig 27).

These mouthguards can be customised to suite the requirements of different sports. At the moment there are four types of heat and pressure laminated mouthguards ${ }^{91}$.

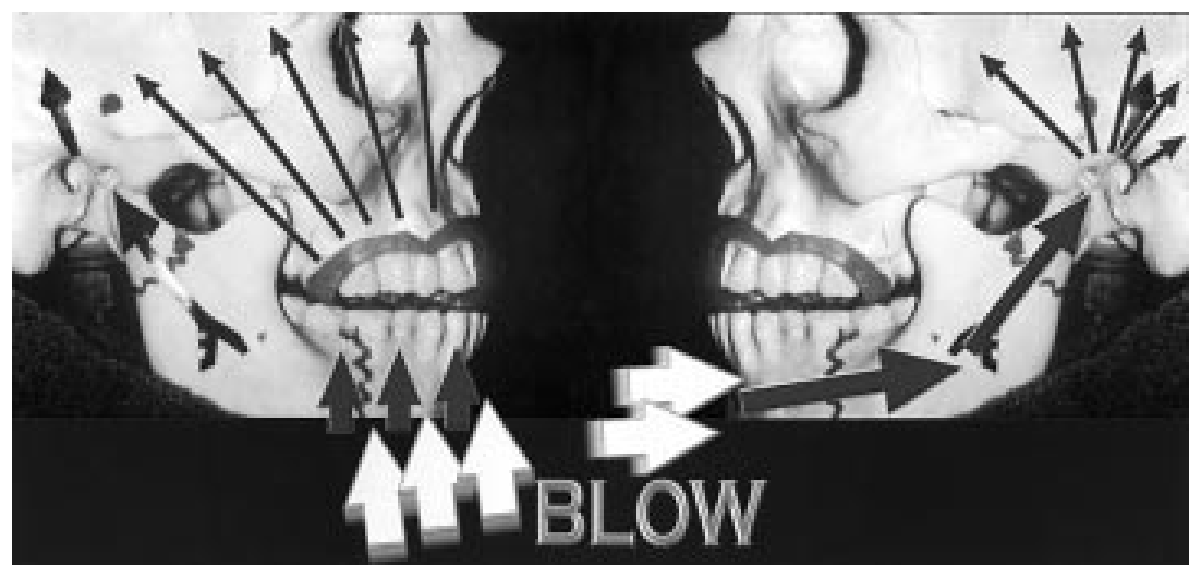

Figure 22 A mouthguard can dissipate forces from blows to the inferior and anterior aspect of the mandible. 

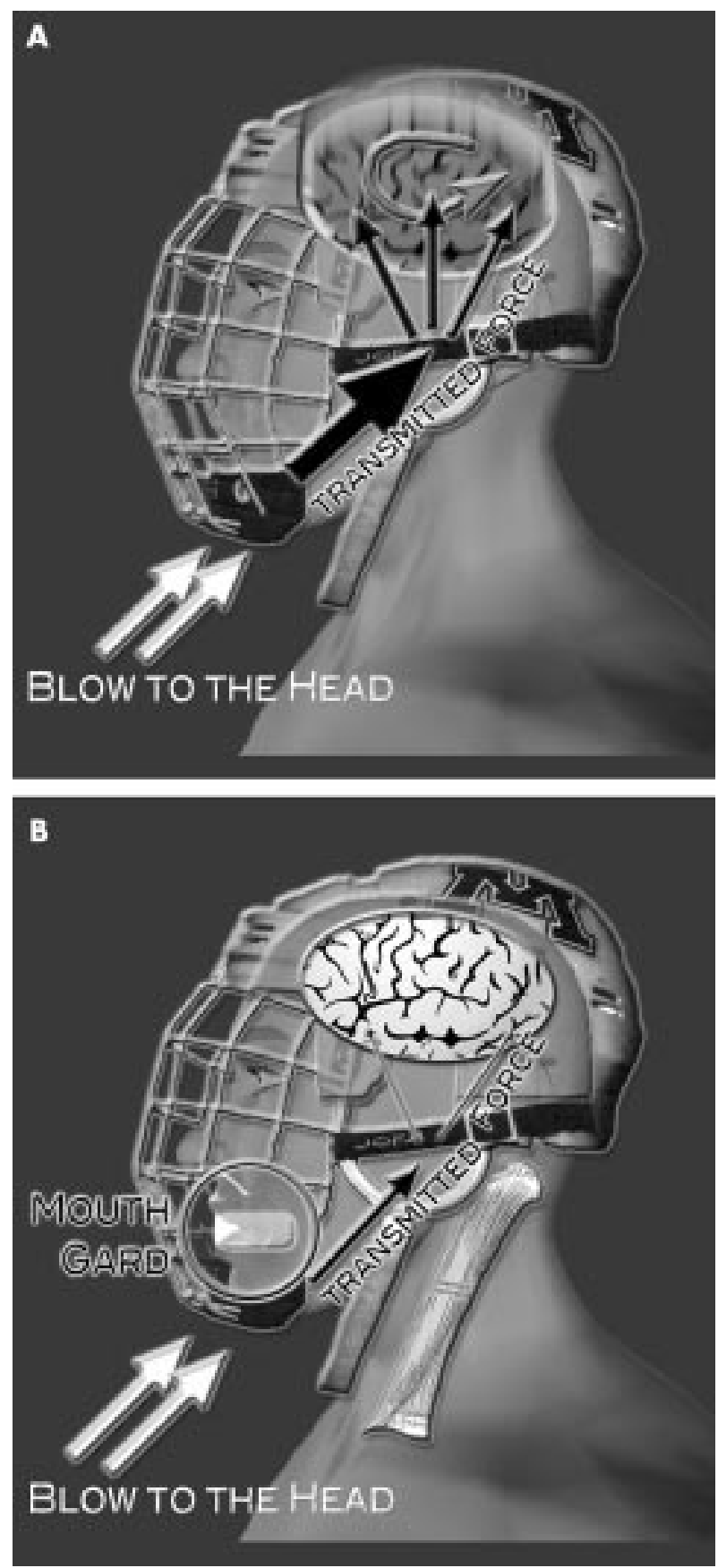

Figure 23 (A) A blow to the head (yellow arrows), such as might be received on the frontal part of a full facemask, may cause mTBI by delivering all the force (large red arrow) from the facemask to the chin, through the lower jaw, through the temporomandibular joint, and then to the brain (three small red arrows) causing shock wave propagation. (B) A custom made mouthguard may absorb all forces delivered to the full facemask (yellow arrows), through the chin, through the lower jaw, through the temporomandibular joint, and then to the brain (small red arrows). A mouthguard may also stabilise the skull through increased activity of the neck muscles induced by clenching to keep the mouthguard in place. Both mechanisms may reduce the risk and severity not only of dental and orofacial injuries, but also of $\mathrm{mTBl}$.

- Type 1, light: with two layers of laminated EVA material with a thickness of $3 \mathrm{~mm}$. This type is designed for wrestling, volleyball, mountain biking, and motocross.

- Type 2, medium: with two layers of laminated EVA material with a thickness of $5 \mathrm{~mm}$. This type is designed for soccer,

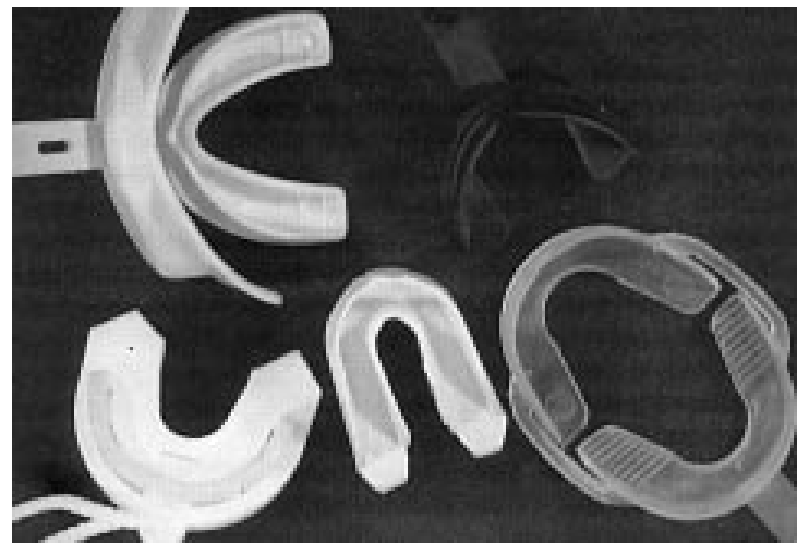

Figure 24 Stock mouthguards. ${ }^{79} 91$

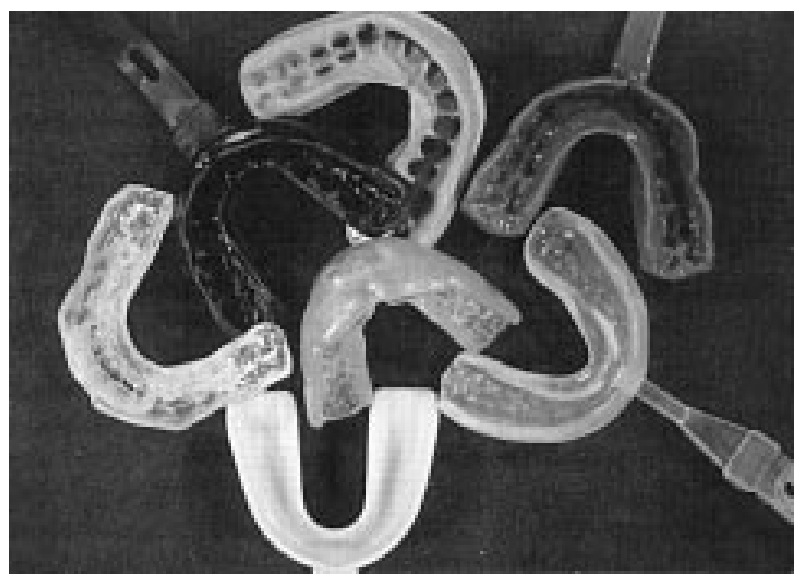

Figure 25 Mouth formed mouthguards. ${ }^{79} 91$

rugby, basketball, softball, rollerblading, skating, and skateboarding.

- Type 3, heavy: with two layers of laminated EVA material with three unique power dispersion bands and $5 \mathrm{~mm}$ thickness. This type is specially designed for baseball, football, racquetball, martial arts, and boxing.

- Type 4, heavy pro: with three layers of laminated EVA material (one hardened layer) with a $5 \mathrm{~mm}$ thickness. This type is specially designed for ice hockey, field hockey, street hockey, and kickboxing.

There is a need to determine scientifically which mouthguard material is best, what material thickness is most effective for injury prevention, and which fabrication technique produces the best results for an individual athlete.

\section{CONCLUSIONS}

The incidence and severity of ice hockey injuries appear to be increasing. Also the costs of treatment of sports related injuries are increasing. The incidence of head and facial injuries is still too high. Even now such injuries are the most common in many countries. It has been shown statistically that there is a correlation between violation of the rules and head and face injuries. A less significant correlation has been registered between facial injuries and accidental events. It is certain that careless performance combined with illegal use of the stick, lack of protective equipment, and the incorrect wearing of helmets, full facemasks, and visors play a decisive role.

Following our analysis, Philippe Lacarrière, Chairman of the IIHF Rules Committee, endorsed in 1998 new rules that make it compulsory to wear helmets and full facemasks (including 

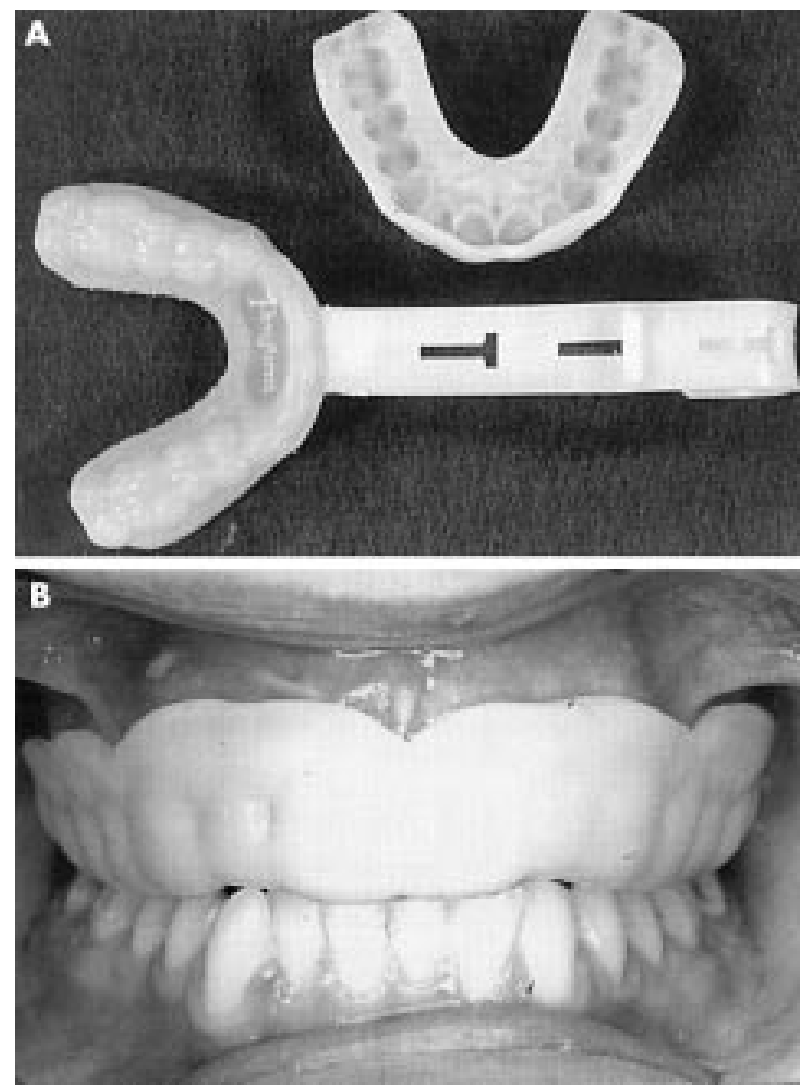

Figure 26 Custom fabricated mouthguard with and without strap attachment. (A) Note the incisal brace. (B) Mouthguard in place. ${ }^{79} 91$

visors), which are in accordance with internationally approved standards organisations (CEN, ISO, ASTM, CSA) (IIHF Rules 223 and 224). ${ }^{50}$ At the moment there are four standards for head and facial protections, but by the end of 2002 there should be a single international standard (ISO EN 10256). ${ }^{33}$ This should represent a big improvement in safety for players, because it will finally be possible to make mandatory the introduction of labels for head and face protection in ice hockey world wide. In Switzerland, these rules have already been introduced (in the 1997/98 season) on a compulsory basis through the SIHA medical committee.

Unfortunately many players wear their helmets with the chinstrap very loosely buckled. Just wearing new protective equipment is not enough; it has to be used and worn properly. For these reasons, the IIHF rules committee has also made mandatory the correct way to wear helmet, visor, and full facemask (IIHF rules 223 and 224) (fig 28) ( $^{50}$ :

- Correct way to wear a helmet (IIHF rule 223): "a helmet shall be worn so that the lower edge of the helmet is not more than one finger-width above the eyebrows, and there should only be enough room between the strap and the chin to insert one finger."

- Correct way to wear a visor (IIHF rule 224): "the visor shall extend down to cover the lower edge of the nose.".

Unfortunately there are still too many players wearing the helmet and facial protection incorrectly. According to the Laws of the game of the Fédération International de Football Association" (FIFA), every football referee must check that the player's equipment is correct before the game starts and before allowing him to re-enter the field (law 4). ${ }^{92}$ The rules committee of the IIHF similarly made it mandatory in 1998 for referees to issue warnings to the team for first violations concerning equipment and they should assess penalties for subsequent violations (rules 223-224, IIHF). ${ }^{50}$
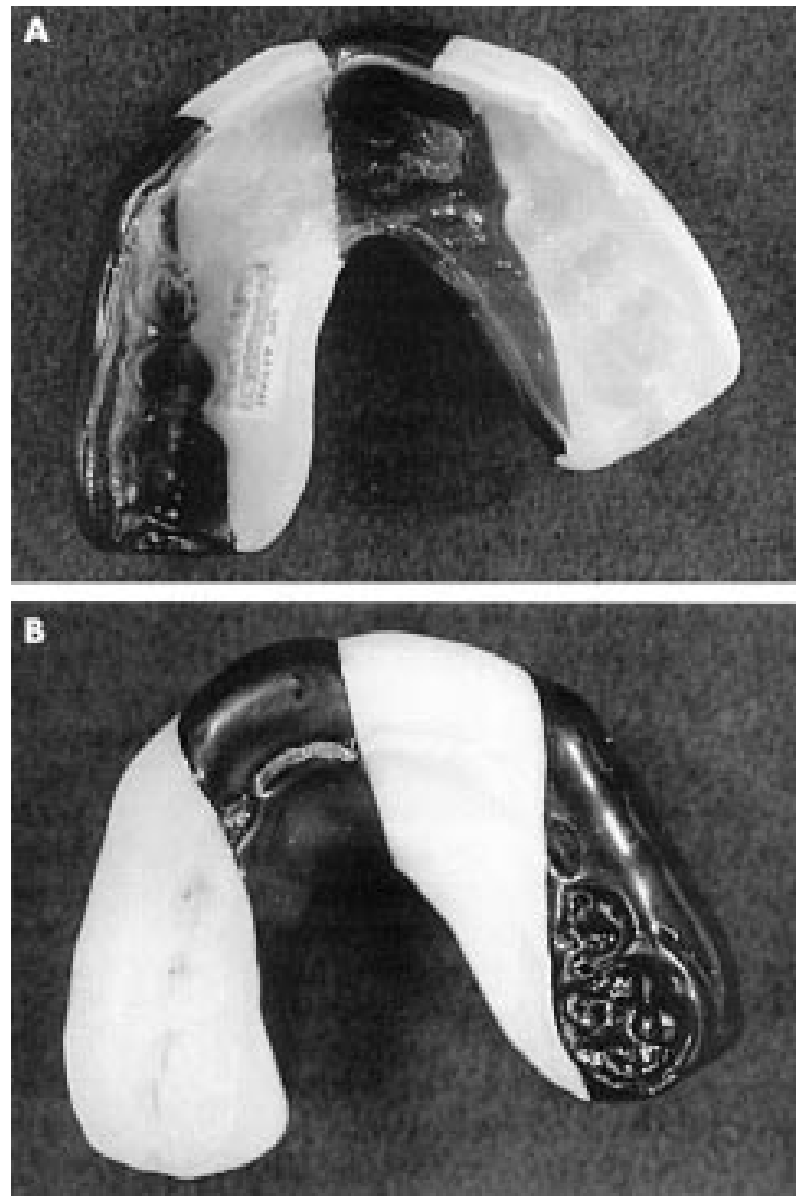

Figure 27 Heat and pressure laminated mouthguards: internal (A) and external (B) aspects. Note indentations of mandibular teeth for stability during contact. ${ }^{79} 91$

Prevention strategies and the introduction of a specific rule against hitting from behind (IIHF Rule 523: "Checking from behind") have been effective in decreasing the number of severe spinal injuries. For these reasons, the IIHF has introduced a new "Head Checking" rule from July 2002, which does not allow any contact to the head. These rules should have the same effect in reducing head injuries, primarily mTBI, which are caused by an acceleration-deceleration blow to the head.

Properly designed mouthguards should be mandatory as devices for the prevention of dental and orofacial injuries and to reduce the incidence and severity of mTBI.

It may therefore be expected that the number of head injuries, primarily mTBI, and avoidable eye and forehead facial injuries will be reduced by eliminating contact with the face and head, through the correct use of helmets, the proper wearing of the visor and full facemask, and the mandatory wearing of properly fitted mouthguards. However, one cannot expect all head and face injuries to disappear.

A further decrease in all kinds of ice hockey injuries can only be achieved by better education of players, coaches and trainers, managers, referees, equipment manufacturers, standards organisations, national sports associations, and doctors.

(1) Players should learn to respect their opponents, to be aware of the hazards of their actions, and to learn the correct techniques of carrying out and receiving body checks and the correct way to wear properly fitted equipment.

(2) Coaches and trainers should teach players about the correct use of the stick, the way to give and take body checks, 


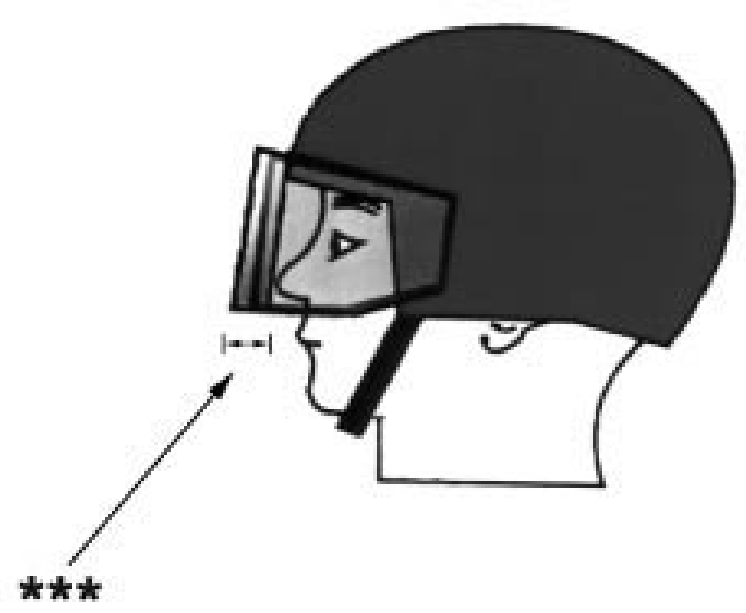

Figure 28 The correct way to wear a visor: the helmet should be worn so that the lower edge of the helmet is not more than one finger width above the eyebrows; there should be room for the insertion of only one finger between the chinstrap and skin; the visor should extend to cover the lower edge of the nose; the distance between the nose and the inside of the visor should not be more than $15 \mathrm{~mm}$ or one finger width $\left({ }^{* * *}\right)$; the visor should always cover the eyes and the nose in the frontal and lateral projections.

and the safe way to hit the boards and fall on the ice. They should further support the correct way to wear protective equipment (see Safer hockey, smarter hockey, better hockey)..$^{33}$

(3) All hockey personnel, especially players and coaches, should be educated about the potential for catastrophic injury, the risk, consequences, and prevention of head, eye, teeth, and neck injuries, and the limitation of protective equipment. ${ }^{94}$

(4) Managers should provide proper equipment and control the proper use of all equipment and the correct way to wear it. The cost of a missed game is much greater than the cost of new equipment.

(5) Referees should enforce the hockey rules and punish more severely head checks, high sticks, and checks from behind. They should also supervise the correct use of all equipment.

(6) Equipment manufacturers should further improve the design, material, and impact performance of the equipment in order to reduce the severity of injuries and to ameliorate the acceptability to the players.

(7) The work of the standards organisations should not end with the publication of standards currently under development. It is possible that standards on the skate blade, sticks, ice rink, and puck will be introduced. The research data supporting the current thinking about head, face, and body protection is constantly being reviewed, revised, and amended. As this occurs, the standards should also be reviewed, revised, and amended.

(8) It is the responsibility of the national associations and all sports organisations to insist on the use of suitable protective equipment. It will be the responsibility of the national authorities to guarantee this high testing standard by monitoring the mark.

(9) Doctors should continue to systematically evaluate and analyse the injury data in order to recognise the potential risk and identify the causal relations.

For these reasons, we have developed an International Sports Injury System (ISIS), which is an expanded computerised version of the Injury Report System (IRS). ${ }^{27}$ ISIS is an internet based database system, which should improve the epidemiological analysis of head, face, and spinal injuries world wide.

\section{Take home message}

Prevention strategies against head checking, properly designed mouthguards, and continuous epidemiological research on an internet based database system (ISIS) are all necessary to reduce the number and severity of ice hockey injuries world wide, as well as to create the basis for further research to improve equipment, rules, and training schedules.

ISIS should also make available an internationally compatible system for the continuous monitoring of the risk factors, the protective effects of the equipment, and the effects of changes in rules through the years. Epidemiological research contributes to an increasing understanding of the incidence and mechanism of injury and has the ultimate goal of reducing risk. All these steps are necessary to create the basis of further research to improve equipment, rules, and training schedules.

\section{ACKNOWLEDGEMENTS}

Some of the above data were collected during the Eighth International Symposium of the International Ice Hockey Federation (IIHF) on Medicine and Science in Ice Hockey in May 1998 at the University Hospital Zurich, Balgrist. Special thanks go to all participants at this symposium, who helped to further improve the safety of ice hockey through their presentations, posters, and handouts. The IIHF medical committee made this symposium possible. We acknowledge their outstanding work. We also extend special thanks to Dr Dent René Fasel, President of the IIHF, and Prof. Dr.med. Christian Gerber, Chairman and Director of the Department of Orthopaedics at the University of Zurich, for giving us the opportunity to organise such a wonderful symposium.

\section{Authors' affiliations}

N Biasca, Head of Orthopaedic Surgery and Co-Head of Trauma Surgery, Spital Oberengadin, CH-7503 Samedan (St Moritz), Switzerland

S Wirth, Orthopaedic Clinic, Spital Oberengadin

Y Tegner, Winternet, Institution of Health Sciences, Luleå University of Technology, Hedenbrovägen, Boden and The Ermine Clinic,

Timmermansgatan 60, SE-972 33 Luleå, Sweden

\section{REFERENCES}

1 Biasca N, Battaglia H, Simmen HP. Analyse typischer Eishockey-Verletzungen. SUVA monographie unfallmedizin no. 6. Luzern SUVA, 1995.

2 Stoner LJ, Kreating M. Hockey equipment: safety or an illusion? In: Castaldi CR, Bishop PJ, Hoerner EF, eds. Safety in ice hockey: volume 2, ASTM STP 1212. Philadelphia: American Society for Testing and Materials, 1993:183-91.

3 Odelgard B. The development of head, face, and neck protectors for ice hockey players. In: Castaldi CR, Hoerner EF, eds. Safety in ice hockey: volume 2, ASTM STP 1050. Philadelphia: American Society for Testing and Materials, 1989;220-34.

4 Pashby T. Eye protection in ice hockey: an historical review. In: Castaldi CR, Bishop PJ, Hoerner EF, eds. Safety in ice hockey: volume 2, ASTM STP 1212. Philadelphia: American Society for Testing and Materials, 1993: 159-63.

5 Dixon JL, Brodie IKR. The new ISO standards for ice hockey helmets and face protectors: moving toward International Standards harmonization and conformity. In: Castaldi CR, Bishop PJ, Hoerner EF, eds. Safety in ice hockey: volume 2, ASTM STP 1212. Philadelphia: American Society for Testing and Materials, 1993:192-213.

6 Groger A. Ten years of ice hockey-related-injuries in the German Ice Hockey Federation: a ten years prospective study/532 international games. SportveretzSportschaden 2001;15:82-6.

7 Clayton P. A review of head injury data in Canadian hockey league with an emphasis on the incidence of concussion. In: Ashare A, ed. Third international symposium on safety in ice hockey. [Abstract.] Philadelphia: ASTM, 1997.

8 Dick RW. Injury in collegiate ice hockey with an emphasis on injuries to the head. In: Ashare A, ed. Third international symposium on safety in ice hockey. [Abstract.] Philadelphia: ASTM, 1997.

9 Biasca N. Review and consequences of the typical ice hockey related injuries in the Swiss lce Hockey Association (SIHA) 1996-1998. In: Biasca N, Montag WD, Gerber C, eds. Safety in ice hockey: Eighth International Symposium of the International lce Hockey Federation IIHF. Zurich: IIHF, 2000:36-52. 
10 Tegner Y. Concussion experiences: Swedish elite ice hockey league: International Symposium on Concussion in Sport [abstract]. Br J Sports Med 2001;35:376

11 Biasca N, Agosti R, Tegner T, et al. Procedures after minor traumatic brain injury $(\mathrm{mTB})$ in ice hockey to prevent neurological sequelae: International Symposium on Concussion in Sport [abstract]. Br J Sports Med 2001;35:368

12 Delaney JS, Brien SE, Baron E. Comparative review of USA consumer product safety board data for soccer, ice hockey, and American Football from 1990 to 1999: International Symposium on Concussion in Sport [abstract]. Br J Sports Med 2001;35:370.

13 Meewisse M, Burke C. NHL Concussion program: Internationa Symposium on Concussion in Sport [abstract]. Br J Sports Med $2001 ; 35: 375$

14 Roberts WO, Brust JD, Leonard B. Youth ice hockey tournament injuries: rates and patterns compared to season play. Med Sci Sports Exerc 1999:31:46-51.

15 Pashby T, Carson JD, Ordogh D, et al. Eliminate head-checking in ice hockey. Clin J Sport Med 2001;11:211-13.

16 Honey CR. Brain injury in ice hockey. Clin J Sport Med 1998;8:43-6.

17 Tegner Y, Lorentzon R. Concussion among Swedish elite ice hockey players. Br J Sports Med 1996;30:252-5.

18 Tegner Y, Back B. Injury pattern in Swedish elite ice hockey. Hygiae 2000;109:204.

19 LaPrade RF. Ice hockey injuries at the collegiate level. Sports medicine \& hockey: a summit for the NHL and beyond. Toronto: American Orthopedic Society for Sports Medicine (AOSSM) and National Hockey League Team Physician Society (NHLTPS), 2001:37-45.

20 Burke CJ. Definition, incidence and initial assessment of concussion. Sports medicine \& hockey: a summit for the NHL and beyond. Toronto: American Orthopedic Society for Sports Medicine (AOSSM) and National Hockey League Team Physician Society (NHLTPS) 2001:107-8.

21 Molsa JJ, Tegner Y, Alaranta H, et al. Spinal cord injuries in ice hockey in Finland and Sweden from 1980 to 1996. Int J Sports Med 1999 20:64-7

22 Tator CH, Carson JD, Edmoonds VE. Spinal injuries in ice hockey. Clin J Sports Med 1998;17:183-94.

23 Tator CH, Carson JD, Cushmann R. Prevention of spinal injuries in ice hockey. In: Biasca N, Montag WD, Gerber C, eds. Safety in ice hockey: Eighth International Symposium of the International lce Hockey Federation IIHF. Zurich: IIHF, 2000:54-62.

24 Tator C. Neck injuries in ice hockey: a recent, unsolved problem with many contributing factors. Clin Sports Med 1987;6:101-15.

25 Tator CH. Spinal injuries in hockey. Sports medicine \& hockey: a summit for the NHL and beyond. Toronto: American Orthopedic Society for Sports Medicine (AOSSM) and National Hockey League Team Physician Society (NHLTPS), 2001:123-30.

26 Reynen PD, Clancy WG. Cervical spine injury, hockey helmets and facemasks. Am J Sports Med 1994;22:167-70.

27 Biasca N, Yelverton T. International Sports Injury System-ISIS. Sports medicine \& hockey: a summit for the NHL and beyond. Toronto: American Orthopedic Society for Sports Medicine (AOSSM) and National Hockey League Team Physician Society (NHLTPS), 2001:15-36

28 Pashby T. Canadian Ophthalmological Society (COS) Survey 1972-2001. Personal communication.

29 Kraus JF, Anderson BD, Mueller CE, The effectiveness of a special ice hockey helmet to reduce head injury in collegiate intramural hockey. Med Sci Sports Exerc 1970;4:162-4.

30 Fekete JF, Path MC, Fredericton NB. Severe brain injury and death following minor hockey accidents: the effectiveness of the safety helmet of Amateur Hockey Players. Can Med Assoc J 1968;99:1234-9.

31 Canadian Standards Association, 178 Rexdale Boulevard, Rexdale, Toronto, M9W1R3 Canada.

32 Schneider KP. Control investigation by TÜV product service Munich of new European law "PSA" and its expected achievement for the safety of ice hockey players. In: Biasca N, Montag WD, Gerber C, eds. Safety in ice hockey: Eighth International Symposium of the International lce Hockey Federation IIHF. Zurich: IIHF, 2000:136-7.

33 Mackenzie K. International equipment standards and safety in hockey. In: Biasca N, Montag WD, Gerber C, eds. Safety in ice hockey: Eighth International Symposium of the International lce Hockey Federation IIHF Zurich: IIHF, 2000:138-40.

34 Bishop PJ. Biomechanics of sports protective equipment in ice hockey to prevent injuries. In: Biasca N, Montag WD, Gerber C, eds. Safety in ice hockey: Eighth International Symposium of the International lce Hockey Federation IIHF. Zurich: IIHF, 2000:36-52.

35 Bishop PJ, Arnold J. The effectiveness of hockey helmets in limiting localized loading on the head. In: Castaldi CR, Bishop PJ, Hoerner EF, eds. Safety in ice hockey: volume 2, ASTM STP 1212. Philadelphia: American Society for Testing and Materials, 1993:175-82.

36 Bishop PJ. Impact performance characteristics of hockey helmets with liners of differing thickness, In: Ashare A, ed. Third international symposium on safety in ice hockey. Philadelphia: American Society for Testing and Materials, 1997:112-17.

37 Gennerelli TA, Thibault LE, Graham DI. Diffuse axonal injury: an important form of traumatic brain damage. The Neuroscientis 1998;4:202-15

38 Graham DI, McIntosh TK, Maxwell WL, et al. Recent advances in neurotrauma. J Neuropathol Exp Neurol 2000;59:641-51.

39 Kelly JP. Return to play following a concussion: International Symposium on Concussion in Sport [abstract]. Br J Sports Med 2001;35:372.
40 Biasca N, Battaglia H, Tegner Y. Diagnose und Behandlungsvorschläge der Commotio cerebri bei Kontakt- und Kampf-sportarten: Beispiel im Eishockey. Schweizerische Ärtzezeitung 1999;80:595-8.

41 Echemendia RJ, Putukian M, Mackin RS, et al. Neuropsychological tes performance prior to and following sports-related mild traumatic brain injury. Clin J Sport Med 2001;11:22-31.

42 Rabadi MH, Jordan BD. The cumulative effect of repetitive concussion in sports. Clin J Sport Med 2001;11:194-8.

$43 \mathrm{http}: / /$ www.hockeyinjuries.com/whatsnew/whatsnew.asp

44 Castaldi CR. The sports mouthguard: its use and misuse in ice hockey. In: Castaldi CR, Bishop PJ, Hoerner EF, eds. Safety in ice hockey: volume 2. ASTM STP 1212. Philadelphia: American Society for Testing and Materials, 1993:164-74.

45 Ranalli DN. Prevention of sports-related traumatic dental injuries. Dent Clin North Am 2000;44:35-51.

46 McIntosh AS. Equipment testing and concussion: International Symposium on Concussion in Sport [abstract]. Br J Sports Med 2001;35:374-5.

47 Naunheim RS, Standeven J, Richter C, et al. Comparison of impact data in hockey, football and soccer. J Trauma 2000;48:938-4 1.

48 Gadd CW. Use of weighted-impulse criterion for estimating injury hazard. Proceedings of the tenth Stapp car crash conference. New York: Society of Automobile Engineers, Inc, 1966:12 (paper 660793).

49 Society of Automobile Engineers. Human tolerance to impact conditions as related to motor vehicle design, SEA J885a, SAE information report. SAE handbook. New York: Society of Automobile Engineers, Inc, 1966.

50 International Ice Hockey Federation (IIHF). Official rule proposal 2002. Zurich, IIHF, 2002

51 Piccininni P. Mouthguards and concussion prevention: International Symposium on Concussion in Sport [abstract]. Br J Sports Med $2001 ; 35: 375$.

52 International Ice Hockey Federation (IIHF). Official rule book 1998-2002. Zurich: IIHF, 2002.

53 Clayton P. Head/facial injury study, Canadian Hockey League 1991-1992, Final data summary, International Hockey of Excellence. Hockey Canada. Olympique Saddledome, Box 1060, Calgary, Alberta T2P 2K8, Canada, 1992.

54 Benson BW, Mohtadi NG, Rose MS, et al. Head and neck injuries among ice hockey players wearing full face shields vs half face shields. JAMA 1999;282:2328-32.

55 Biasca N, Tegner $Y$. Head and face injuries in ice hockey: role of the protective equipment. Br J Sports Med 2002; in press.

56 LaPrade RF, Broxterman RJ. The single strap helmet fixation system in intercollegiate ice hockey: a source of variable face protection. In Ashare A, ed. Third international symposium on safety in ice hockey. Philadelphia: American Society for Testing and Materials, 1997:124-9.

57 Pettersson $\mathbf{M}$, Lorentzon R. Ice hockey injuries: a 4-year prospective study of a Swedish elite ice hockey team. Br J Sport Med 1993;27:25 1-4.

58 Lorentzon R, Wedren H, Pietila T. Incidence, nature and causes of ice hockey injuries: a three-year prospective study of a Swedish elite ice hockey team. Am J Sports Med 1988;16:392-6.

59 Tegner $Y$, Lorentzon R. Ice hockey injuries: incidences, nature and causes. Br J Sports Med 1991;25:87-9.

60 Biörkenheim JM, Syvahuoko I, Rosenberg PH. Injuries in competitive junior ice hockey. Acta Orthop Scand 1993;64:459-61.

61 Stuart MJ, Smith A. Injuries in junior A ice hockey: a three-year prospective study. Am J Sports Med 1995;23:451-61.

62 LaPrade RF, Burnett QM, Zarzour R, et al. The effect of the mandatory use of face masks on facial lacerations and head and neck injuries in ice hockey: a prospective study. Am J Sports Med 1995;23:773-5.

63 Murrey TM, Livingston LA. Hockey helmets, face masks and injurious behavior. Pedriatics 1995;95:419-21.

64 Voaklander DC, Saunders LD, Quinnes HA, et al. Epidemiology of recreational and old-timer ice hockey injuries. Clin J Sport Med 1996;6:15-21.

65 Rampton J, Leach T, Therrien SA, et al. Head, neck and facial injuries in ice hockey: the efffect of protective equipment. Clin J Sport Med 1997;7:162-7

66 Mölsa J, Kujala U, Näsman O, et al. Injury profile in ice hockey from the 1970s through the 1990s in Finland. Am J Sports Med 2000;28:322-7.

67 Stuart MJ, Smith AM, Malo-Ortiguera SA, et al. A comparison of facial protection and the incidence of head, neck and facial injuries in junior $A$ hockey players: a function of individual playing time. Am J Sports Med 2002;30:39-44

68 Juhn MS, Brolinson PG, Duffey T, et al. Violence and injury in ice hockey. Clin J Sport Med 2002;12:46-51.

69 Walsh S. A proposal for the use of the half face, clear plastic visor for National Collegiate Athletic Association Hockey. In: Castaldi CR, Hoerner EF, eds. Safety in ice hockey: volume 2, ASTM STP 1050 Philadelphia: American Society for Testing and Materials, 1989:55-7.

70 Reid SR, Losek JD. Factors associated with significant injuries in youth ice hockey players. Pediatr Emerg Care 1999;15:310-13

71 Mueller FO. Fatalities from head and cervical spine injuries occurring in tackle football: 50 years experience. Clin J Sport Med 1998; 17:169-82.

72 Torg JS, Thibault L, Sennett B, et al. The pathomechanics and pathophysiology of cervical spinal cord injury. Clin Orthop 1995;321:259-69.

73 Tator CH, Edmonds VE, Lapczak L. Spinal injuries in ice hockey: review of 182 North American cases and analysis of etiologic factors. In: Castaldi CR, Bishop PJ, Hoerner EF, eds. Safety in ice hockey: volume 2, ASTM STP 1212. Philadelphia: American Society for Testing and Materials, 1993:11-20. 
74 International Ice Hockey Federation (IIHF). Official rule book 1994. Zurich: IIHF, 1994

75 Bishop PJ, Norman RW, Wells RP. A study of selected mechanical factors involved in neck injuries in ice hockey. Biomechanics IXB. In: Proceeding of the 9th International Congress of Biomechanics, Waterloo, Canada, August 1985. Champaign, Illinois: Human Kinetics Publishers, 167-71

76 Bishop PJ, Norman RW, Wells RP, et al. Changes in the center of mass and moment of inertia of a head form induced by a hockey helmet and face shield. Can J App/ Sport Sci 1983:8:19-25.

77 Bishop PJ, Wells RP. Cervical spine fractures: mechanisms, neck load, and methods of prevention. In: Castaldi CR, Hoerner EF, eds. Safety in ice hockey: volume 2, ASTM STP 1050. Philadelphia: American Society for Testing and Materials, 1989:71-83.

$78 \mathrm{Sim} \mathbf{F H}$, Chao EY. Injury potential in modern ice hockey. Am J Sports Med 1978;15:30-40.

79 Piccininni P. Typical dental injuries in ice hockey with and without face protection and recent advances in mouthguard design. In: Biasca $\mathrm{N}$, Montag WD, Gerber C, eds. Safety in ice hockey: Eighth International Symposium of the International lce Hockey Federation IIHF. Zurich: IIHF, 2000:95-103

80 Sane J. Dental trauma in contact team sports. Endod Dent Traumatol 1988;4:164-9a.

81 Morrow RM, Seals RR, Barnwell GM. Report of a survey of oral injuries in male college and university athletes. Journal of Athletic Training National Athletic Trainers' Association, 1991;26:339-42.

82 Kujaya UM. Acute injuries in soccer, ice hockey, volleyball, basketball, judo and karate: analysis of national registry data. BM 1995:311:1465-8.

83 Tesini DA, Soporowski NJ. Epidemiology of orofacial sports-related injuries. Dent Clin North Am 2000;44:1-18.
84 Stenger JM, Lawson EA, Wright JM, et al. Mouthguards: protection against shock to head, neck and teeth. Journal of the American Dental Association 1964;69:273-82.

85 Hickey JC, Morris AL, Carlson LD, et al. The relation of mouth protectors to cranial pressure and deformation.Journal of the American Dental Association 1967;74:735-40.

86 Chapman PJ. The bimaxillary mouthguard: improved protection against orofacial and head injury in sport. Aust J Sci Med Sport 1986; 17:25-8.

87 Porter M, O'Brien M. The "Buy-Max" mouthguard: oral, peri-oral and cerebral protection for contact sports. J Ir Dent Assoc 1994;40:98-101.

88 Ranalli DN. Prevention of sports-related traumatic dental injuries. Dent Clin North Am 2000;44:35-51.

89 McCrory P. Do mouthguards prevent concussion? Br J Sports Med $2001 ; 35: 81-2$

90 Barth JT, Freeman JR, Winters JE. Management of sports-related concussions. Dent Clin North Am 2000;44:67-83.

91 Piccininni P. Playsafe: the leading custom fabricated sports mouthguard worldwide. College Park, 777 Bay Street Box 111, Toronto, ON M5g 2C8, Canada, 2000.

92 Fédération Internationale de Football Association (FIFA). Laws of the games 1997. Zurich: FIFA, 1997.

93 Ashare AB. Heads up hockey: USA program to decrease the risk for paralyzing cervical spine fractures. In: Biasca N, Montag WD, Gerber C, eds. Safety in ice hockey: Eighth International Symposium of the International lce Hockey Federation IIHF. Zurich: IIHF, 2000:63-8.

94 Smith AM, Stuart N, Wiese-Bjornstal DM, et al. Predictors of injury in ice hockey players: a multivariate multidisciplinary approach. Am J Sports Med 1997;25:500-7.

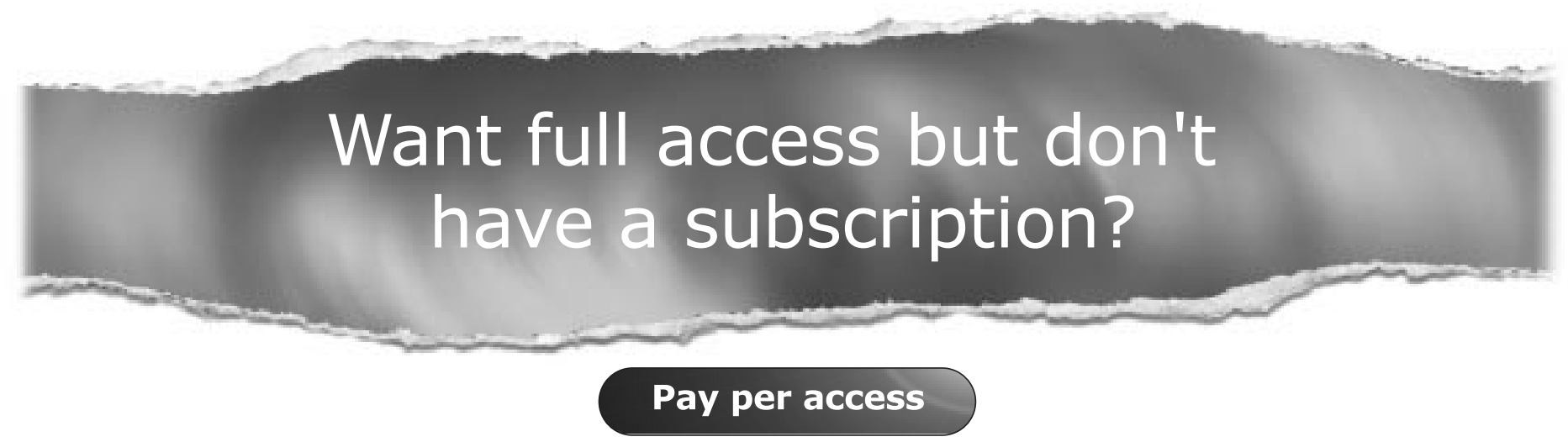

For just US\$25 you can have instant access to the whole website for 30 days. During this time you will be able to access the full text for all issues (including supplements) available. You will also be able to download and print any relevant pdf files for personal use, and take advantage of all the special features British Journal of Sports Medicine online has to offer.

\section{www.bjsportmed.com}

